Portland State University

PDXScholar

11-8-1989

\title{
Intercultural Adjustment Problems of Costa Rican Students in the United States
}

Patricia Gonzalez

Portland State University

Follow this and additional works at: https://pdxscholar.library.pdx.edu/open_access_etds

Part of the International and Intercultural Communication Commons

Let us know how access to this document benefits you.

\section{Recommended Citation}

Gonzalez, Patricia, "Intercultural Adjustment Problems of Costa Rican Students in the United States" (1989). Dissertations and Theses. Paper 4054.

https://doi.org/10.15760/etd.5938

This Thesis is brought to you for free and open access. It has been accepted for inclusion in Dissertations and Theses by an authorized administrator of PDXScholar. Please contact us if we can make this document more accessible: pdxscholar@pdx.edu. 
AN ABSTRACT OF THE THESIS OF Patricia Gonzalez for the Master of Arts in Speech Communication presented November $8,1989$.

Title: Intercultural Adjustment Problems of Costa Rican students in the United States.

APPROVED BY THE MEMBERS OF THE THESIS COMMITTEE:

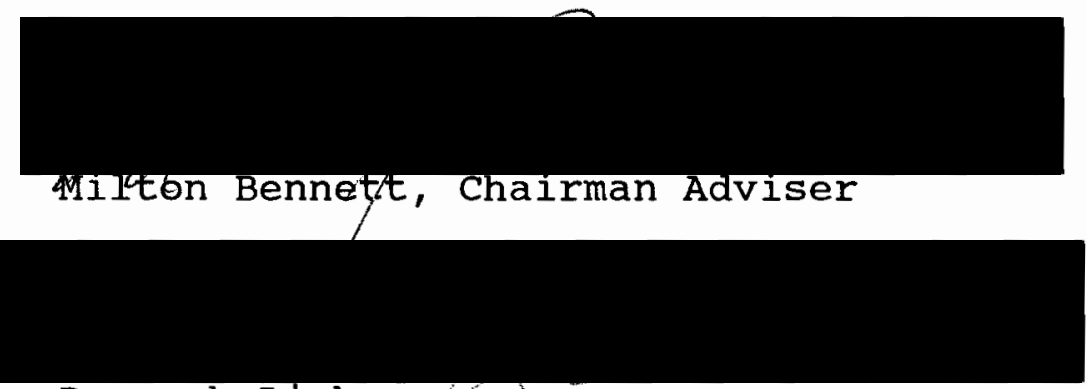

Devorah Lieberman

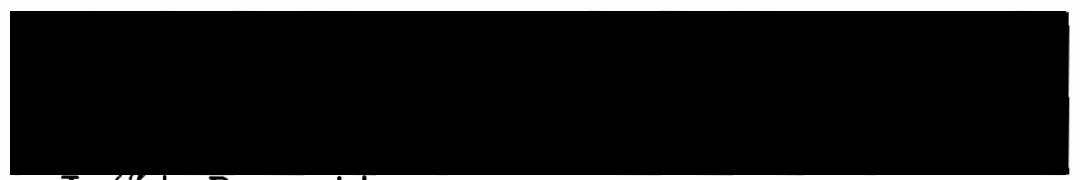

Jafiet Bennett

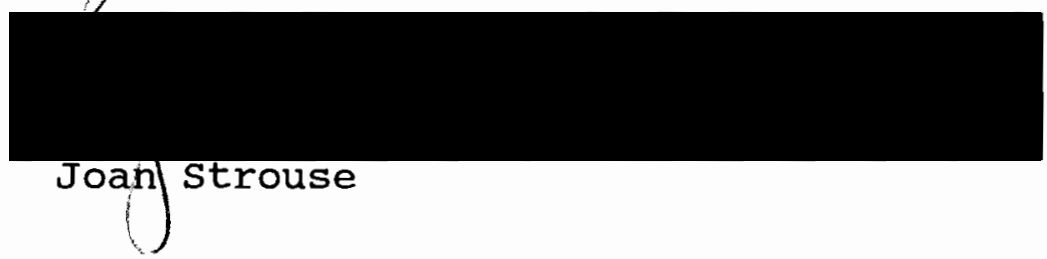

The purpose of this study is to determine the adjustment problems costa Ricans face while living and studying in the United states. The main concern of this thesis is to identify the intercultural communication problems that arise fundamentally from differences in value systems. 
The population for this study was Costa Rican students attending college for a minimum of two years. Eleven subjects were interviewed, including three undergraduate and eight graduate students who plan to remain in the United states an average of three and one-half years.

This study constitutes an exploratory approach that combines a descriptive method as a means of data collection with grounded theory as a qualitative method of data analysis. In this descriptive research project, the researcher uses the "in-depth" interview approach as the data-gathering tool to answer the research question. In order to collect the information, this researcher personally interviewed the subjects of the study.

Grounded theory constitutes the second methodological approach used in this study. Three main phases were followed. Phase one of the research involved the generation of themes from three major sources: Literature Review, especially Sharma's "Foreign Students Problems Inventory'; an interview with Raul Martinez, Director of the International student Services at Portland state University; and a preliminary survey.

In phase two, the researcher looked for new themes arising from Mr. Martinez's interview and the preliminary survey results, and selected themes from the reviewed literature for follow-up in the interviews. This information allowed the researcher to develop an inventory 
of expected intercultural adjustment problems of costa Rican students and later to generate an interview schedule that was used as a data collection tool.

In phase three, the information gathered through the interviews was analyzed in terms of the concepts, both general and specific, mentioned in the Literature Review and the Inventory of Problems of Costa Rican Students.

An analysis of the results of the follow-up interviews in general supported propositions found in the literature review.

Five of the eight most supported themes regarding adjustment problems were relational issues such as relationships with classmates, establishing friendships and family relations and social interaction with Americans in general.

A major conclusion of this study is that even though adjustment problems reported by Costa Rican students are generally the same as those mentioned in the literature for all foreign students, the causes of these problems may be unique to Costa Ricans due to the specific difference in value systems between Costa Rica and the U.S.

This study concludes that, in general, there is a lack of knowledge of the American culture on the part of the Costa Rican students, which is the cause of frustration and disorientation that often has a negative effect on their adjustment. 
A potential application of this study is to design a training program for future costa Ricans coming to the U.S., based on the results of this thesis, that will better suit this population's needs in adjusting to the American culture. The emphasis of this training program will be in focusing on value differences between the Costa Rican and American cultures. The purpose of this training program will be to start building a bicultural perspective in the Costa Rican students that will better equip them to deal with differences. 
INTERCULTURAL ADJUSTMENT PROBLEMS OF

COSTA RICAN STUDENTS IN THE

UNITED STATES

By

PATRICIA GONZALEZ

A thesis submitted in partial fulfillment of the requirements for the degree of

MASTER OF ARTS

in

SPEECH COMMUNICATION

Portland state university

1989 
TO THE OFFICE OF GRADUATE STUDIES:

The members of the committee approve the thesis of Patricia Gonzalez presented November 8, 1989.

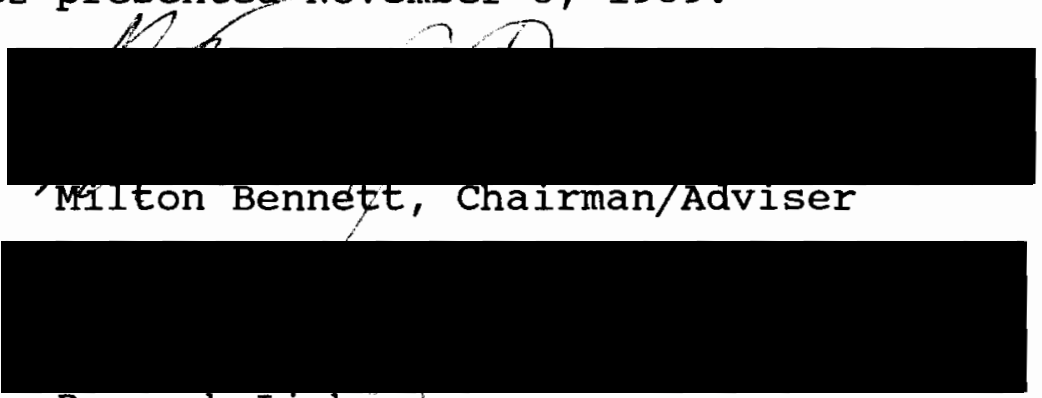

Devorah Iieberman

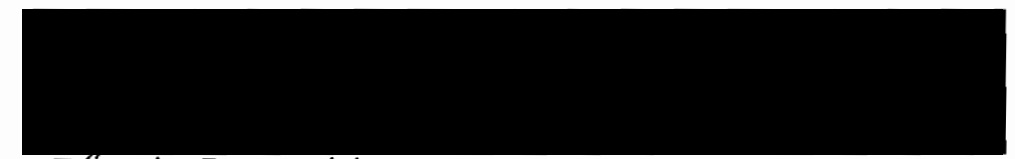

Janet Bennett

I

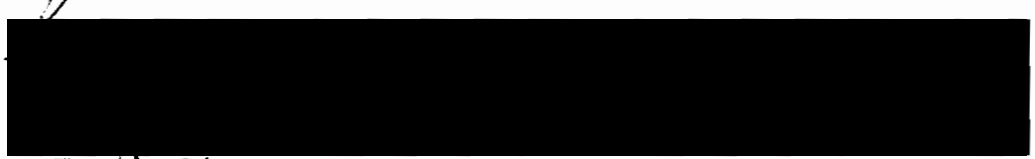

Joan Strouse

APPROVED:

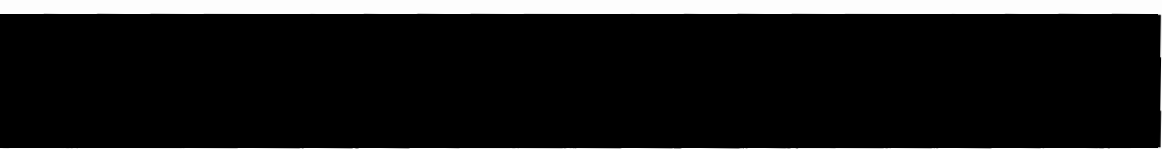

Theodore G. Grove, Chair

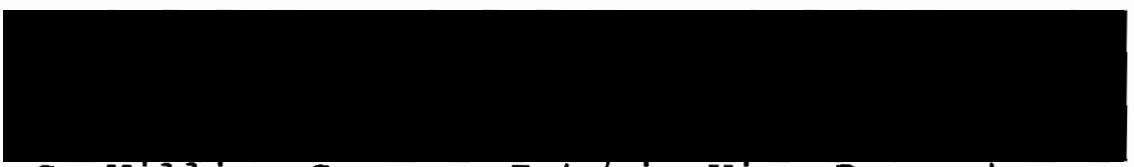

C. William Savery, Interim Vice Provost

for Graduate studies and Research 
DEDICATED TO

All the people in the United States and

in Costa Rica who made this thesis possible, and especially to Nien, my daughter, who, I hope, one day will understand the meaning of all we have been through. 


\section{ACKNOWL EDGEMENTS}

I am indebted to a number of individuals who have supported and assisted me in this project.

First, I would Iike to give special thanks to Dr. Milton Bennett, my academic adviser and Chairman of my Committee, whose guidance and support proved invaluable to me. I very much appreciate his willingness to help me through this process even during his sabbatical leave.

To all the members of my Committee I extend my grateful appreciation for their help in providing valuable recommendations for this study.

I wish to thank in a special way, Sandy Carter and Mark Garber for their editorial skills that proved invaluable, their understanding, and their friendship.

Grateful appreciation goes to sister olivianne Santilli, not only for typing skills but for her understanding and support.

I am also indebted to all my Costa Rican and American friends whose support and encouragement mean a lot to me. I would not mention any names for fear that I might omit one, but you all are in my heart.

I am most appreciative of the love and encouragement of my husband, Jimen Chan. It was hard to be supportive of 
each other as we were both involved in similar projects. To him my special congratulations. I know how much the achievement of this degree means to him.

Finally, my sincere gratitude to my families, both Costa Rican and American. Particularly, I want to acknowledge my father, Hernan; my mother, Flory; my sister, Orietta; my uncle, Sergio; and my American parents, Mac and Susan, for their love and spiritual and material support. Without them, the accomplishment of this thesis would not be a reality. If it is nice to have a family, it is wonderful to have two.

God bless you all. 
TABLE OF CONTENTS

PAGE

ACKNOWLEDGEMENTS . . . . . . . . . . . . . iv

LIST OF TABLES . . . . . . . . . . . . . . ix

LIST OF FIGURES . . . . . . . . . . . . . . $\mathrm{x}$

CHAPTER

I INTRODUCTION . . . . . . . . . . . . 1

Problem statement........ 1

Operational Definitions..... . 3

Significance and Justification . . 7

II LITERATURE REVIEW . . . . . . . . . 11

Adjustment Process . . . . . . 11

culture shock

Curves of Adjustment and the

Graph of Emotion Intensity

other Theories

General Adjustment Problems . . . 26

Adjustment Problems of

Foreign Students . . . . . . . . 30

Value systems and the

Adjustment Process . . . . . . . 38

Expected Adjustment Problems of

Costa Rican Students . . . . . . 64

III METHODOLOGY . . . . . . . . . . 67

General Approach . . . . . . 67 


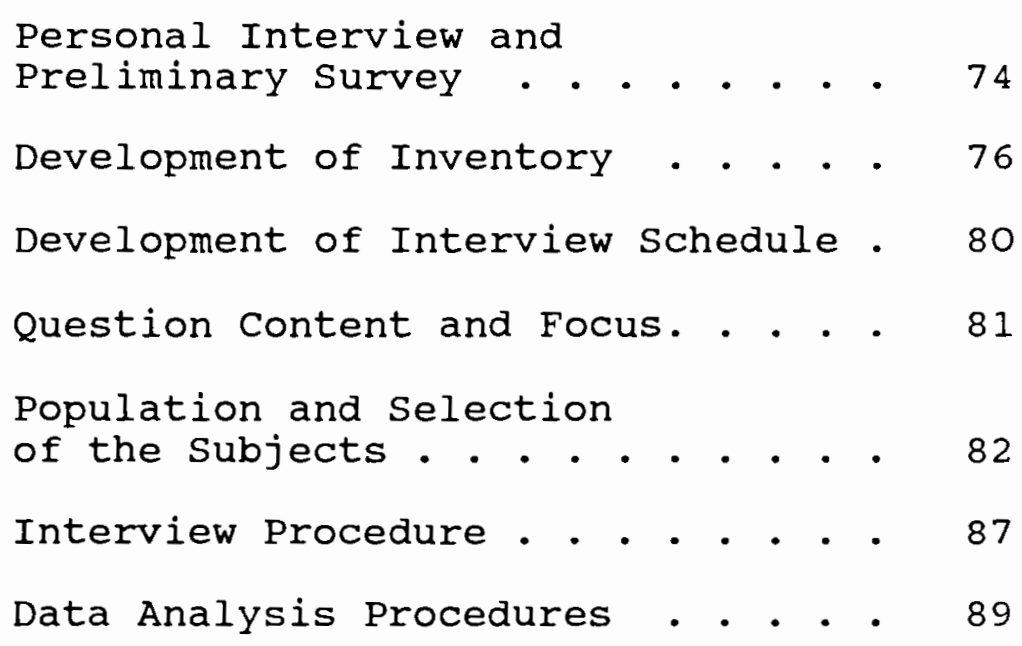

IV RESULTS . . . . . . . . . . . . . 91

Theme I............. . 91

Theme II . . . . . . . . . . . . 94

Theme III . . . . . . . . . 94

Theme IV . . . . . . . . . 97

Theme V............ 101

v DATA ANALYSIS ........... 105

Demographic Data Analysis . . . . 121

VI CONCLUSIONS, LIMITATIONS, APPLICATIONS,

AND FUTURE RESEARCH .......... . 134

Conclusions . . . . . . . . 134

Limitations . . . . . . . . 138

Applications and future research . 140 REFERENCES . . . . . . . . . . . . . . . . 144 
APPENDICES

A Preliminary Survey . . . . . . . . 151

B Inventory of Expected Problems of Costa Rican Graduate Students . . . . 167

c Interview Schedule. . . . . . . . 170 


\section{LIST OF TABLES}

TABLE

I Summary of the Adjustment Problems Faced by Costa Rican Students . . . . $12 \emptyset$ 


\section{LIST OF FIGURES}

\section{FIGURE}

1. U-Shaped Curve of Adjustment . . . . 18

2. W-Shaped Curve of Adjustment . • • • . 19

3. Kohls' W-Shaped Curve of Adjustment . 21

4. Graph of Emotional Intensity . . . . . 22

5. Kohls' Comparative Model . . . . . . 41 
CHAPTER I

INTRODUCT ION

PROBLEM STATEMENT

The purpose of this study is to determine adjustment problems costa Ricans face while living and studying in the United states. The main concern of this thesis is to identify the intercultural communication problems that arise fundamentally from differences in value systems.

People such as businessmen, foreign students, and consultants visiting other cultures often carry their own frame of reference, their cultural background, their usual and natural way of living as well as their perception of the world. In Kohl's words, "we are doomed to carry our complete load of cultural baggage wherever we go" (1984, p. 31).

Berger and Luckman (1967) use the term "primary socialization" to describe the process through which people acquire the values, beliefs, and world view that constitute their cultural frame of reference. It is this primary socialization that motivates people to act, behave and interact with others in a specific way.

When people who have the same background and belong to the same group interact, the possibility of 
misunderstanding is reduced. But, on the contrary, if people with different cultural backgrounds interact, the possibility of misunderstanding and other communication problems increases. Brislin (1984), Condon (1987), and Kohls (1984) talk about the problems caused by differences in behavior, value systems, and perceptions of the world when people from two different cultures interact. Those differences influence people's relationships and their communication encounters (Condon \& Yousef, 1987).

Foreign students, coming from different specific cultures, with different frames of reference, encounter these problems. In the host country, with its particular culture, their interactions are with people having a different frame of reference.

Foreign students face adjustment problems within the culture in which they have chosen to study. Their communicative acts there will be affected by the differences between the cultural and communication patterns they are going to use and those held by host counterparts. The main assumption of this study is that Cosa Rican students in the U.S. will have some problems. Also, the problems Costa Ricans face are expected to be different from the problems that students from other countries might encounter, due to differences in every culture.

The fundamental premise is that there are differences between the American and Costa Rican cultures that affect 
the everyday interaction between costa Rican students and American people, perhaps causing problems in adjustment. The purpose of this study is to identify possible problems that Costa Rican students face in adjustment to the American culture and to analyze them in intercultural communication terms. The study will seek an answer to the following research question:

WHAT PROBLEMS OE CULTURAL ADJUSTMENT DO COSTA RICAN COLLEgE STUDENTS EXPERIENCE WHILE LIVING IN THE UNITED STATES?

\section{OPERATIONAL DEFINITIONS}

Certain concepts are the backbone of this research. Those concepts are defined as follows:

CULTURE: Culture is "an integrated system of learned behavior patterns. - " (Kohls, 1984, p. 17) which are created, shared and reproduced by members of a specific group. It is the entire lifestyle, attitudes, values and beliefs of individuals with the same frame of reference, similar background and experiences.

VALUE SYSTEM: "A value system . . represents what is expected or hoped for, reguired or forbidden. It is not a report of actual conduct, but it is the system of criteria by which conduct is judged and sanctions applied" (Condon, 1987, pp. 50-51).

VALUE ORIENTATION: A value orientation is a particular solution that any given society applies to the 
problems all societies have to face (Condon, 1987). For example, with respect to time sense, according to the Kluckhohn and Strodtbeck's Model (1961), the orientation of some cultures may be ruled by the expectation that "man should learn from history and attempt to emulate the glorious ages of the past" (Kohls, 1985, p. 85). This means that these societies are past-oriented. The approach in other cultures may be present-oriented. That is, "the present moment is everything. Let's make the most of it. Don't worry about tomorrow; enjoy today" (p. 85). In some other cultures, the feeling is that future orientation is the best way to approach time. In those societies, "planning and goal-setting make it possible for man to accomplish miracles. A little sacrifice today will bring a better tomorrow" (p. 85).

COMMUNICATION: This concept here will be defined as something more than only the action of conveying messages through language. So, communication is ". . any behavior that is perceived and interpreted by another, whether or not it is spoken or intended or even within the person's conscious awareness" (Condon, 1984, p. 2).

INTERCULTURAL COMMUNICATION: Intercultural communication "occurs whenever a message producer is a member of one culture and a message receiver is a member of another" (Porter and Samovar, 1985, p. 20). 
INTERCULTURAL COMMUNICATION PROBLEMS: In short, intercultural communication problems are the problems that arise when people holding different value systems interact. "The expectations, perceptions, and experiences that persons from different cultural backgrounds bring into social interaction situations. . " (Albert, 1986, p. 42) count as the main sources for intercultural communication problems. The explanation for this phenomena is that "culture. - is the foundation of communication. And, when cultures vary, communication practices also vary" $(1985, \mathrm{p} .20)$

ADJUSTMENT (ADAPTATION): As Brislin (1984) points out, cultural adjustment refers to "feelings of comfort in the host society" (p. 283). One must feel "at home" rather than a total stranger, and must be able to operate in daily life "without severe stress" (p. 27l) that, according to Brislin, is caused by "the necessity to deal constantly with unfamiliar situations" (p. 169).

Gudykunst and Hammer, in their article entitled "Strangers and Hosts" (1987), quote Ruben's definition of adaptation as follows:

\footnotetext{
- - adaptation is a consequence of an ongoing process in which a system strives to adjust and readjust itself to challenges, changes, and irritants in the new environment. The (adaptation) cycle is triggered when discrepancies between the demands of an environment and the capabilities of a system emerge, creating disequilibrium, or stress. (p. 107 )
} 
Based upon this definition, Gudykunst and Hammer concluded that "intercultural adaptation, . . involves working out a fit between the person and the new cultural environment" (p. 107).

Considering that adjustment is the key word of this study, it is necessary to clarify that adjustment and adaptation are considered synonymous for the purposes of this study. But, they are not associated in any way with the concept of acculturation, also known as assimilation.

Adjustment or adaptation refer to the process that is inherent to the experience of learning another culture, in order to function well within it. Adjustment and adaptation are terms related to living temporarily in another country, as has been suggested in the literature (Gama and Pedersen, 1977).

Acculturation, on the other hand, is "the change in individuals whose primary learning has been in one culture and who take over traits from another culture," according to Marden and Meyer (1968, p. 35). This term is more frequently used to describe the intercultural communication process commonly undergone by immigrants. It is thought to cause permanent effects in the foreigner's behavior, attitudes and world view (Sermol, 1983).

Szalay and Inn (1987) attribute the same meaning to the terms adaptation and acculturation. When defining the concept of cultural adaptation, they say "frequently 
labeled acculturation," indicating that they are interchangeable words. In this thesis, based on the above discussion, "adaptation" and "acculturation" may not be considered to have the same meaning.

STRANGER: The definition provided by Gudykunst and Hammer says that ". . strangers are [people] physically present and participating in a situation (that is, the host culture), but at the same time are outside the situation because they are from a different place (that is, a different culture)" (1984, p. 107). In this study, sojourner, foreign student and visitor will be considered as synonymous with stranger and will be used to describe or refer to the Costa Rican college students.

Furnham indicates that "a number of different groups of people may be classified as sojourners: business people, diplomats, foreign workers, students, and voluntary workers" (1987, p. 43).

According to Schuetz (1944), a stranger is "an adult individual - . who tries to be permanently accepted or at least partially tolerated by the group which he approaches" (p. 499).

\section{SIGNIFICANCE AND JUSTIFICATION}

The importance of this research is that it will provide information that may benefit Costa Rican students, the Intercultural Communication field, organizations. responsible for costa Rican students coming to the U.'s., 
and Americans traveling to Costa Rica. For Costa Rican students, the results of this study may help to ease the process of adjustment of students coming to the U.S., a group that is increasing in number every year. According to information supplied by the American Embassy in Costa Rica to this researcher, 1,200 Costa Ricans come to the U.S. each year as either short-term residents, high school exchanges, or long-term students. Equal numbers of student visitors are predicted from Guatemala, Honduras, and EI Salvador. If immediate measures are taken within the organizations sponsoring the students, these findings might help current students as well.

In relation to the Intercultural Communication field, this research contributes to the available information pertaining to particular cultures and specifically to the subject of intercultural communication problems of costa Rican students in the American culture milieu. There are several cross-cultural studies comparing the U.S. culture and Chinese, Japanese, or Middle Eastern cultures, for instance, while there are but few books in the field of Intercultural Communication regarding Latin American culture. One book compares the American and Latin American cultures, with emphasis on the Mexican culture (Condon, 1985). Another book, Living in Latin America by Raymond L. Gorden (1976), focuses more on customs than on value differences. 
Several studies have researched foreign students in the American culture, including Africans (Veroff, 1963; Pruitt, 1978), and Europeans (Lysgaard, 1954). But, even though Latin Americans were included as a part of a sample in a study about adjustment problems of non-European foreign students (Sharma, 1971), there is no easily obtainable study regarding the adjustment process experienced by only Latin American students.

Therefore, this study constitutes a relevant contribution to the field of Intercultural Communication as it provides information, not currently available, about adjustment problems of Costa Rican students in terms of value differences. This study provides data that could lead to further research on other aspects of intercultural communication, such as re-entry culture shock, more specific aspects of culture shock, and adjustment processes of Latin American data that has not before been available. In addition, the gathered data could be used as the foundation for studying intercultural communication problems of sojourners studying abroad, mainly in the U.S., from the other Central American countries as well as the rest of Latin America.

With respect to the organizations responsible for funding, choosing and supporting Costa Rican students coming to the U.S., the final outcome of the research in question might be useful, to the extent that it provides 
those organizations with information identifying the problems of adjustment that those students face in the American culture. In this light, those organizations will be able to offer cross-cultural orientation programs that satisfy the needs of this particular population. Among those organizations are: the Agency for International Development Costa Rican Mission; the United States of America Agency for International Development (U.S.A.I.D.); and the Experiment in International Living, which is an arm of Partners for International Education and Training (P.I.E.T.), which is a contractor of U.S.A.I.D. Finally, this research is of some benefit to American students traveling to Costa Rica, American professors dealing with foreign students, and American people in general, who are interested in learning about other cultures, specifically the Costa Rican culture. 


\section{LITERATURE REVIEW}

This research is concerned with one major aspect of the intercultural communication field: the adjustment process that is likely to occur when a person moves from one culture to another. In this sense, this study's approach is that differences in value systems are the foundation of the adjustment problems that Costa Rican students might face.

This Chapter constitutes a comprehensive review of the relevant intercultural literature, which is divided into the following categories: general adjustment process; general adjustment problems; adjustment problems of foreign students; value systems and the adjustment problems; and expected adjustment problems of Costa Rican students.

\section{ADJUSTMENT PROCESS}

The individual living, studying or working in another country is a foreigner who discovers that his or her usual and "natural" behavior, norms and the like are not considered "normal" in the host culture.

The case of the student is different from that of a tourist to the extent that the former has to define a way of living while the latter is able to get along well 
without establishing a modus vivendi. The student must learn the norms that regulate the relationship of the hosts, as well as the general communication patterns. This learning process is difficult because individuals outside the group cannot easily see or identify the norms and communicative acts that people within the culture follow or reproduce automatically. To the hosts, the host norms are "visible" (Schild, 1968). To the stranger, they are often invisible.

The literature includes discussions about the problems that sojourners experience when they enter a new culture (e.g., Brislin, 1984; Condon, 1987; Furnham and Bochner, 1986; Kohls, 1984; Tyler, 1987; and Gudykunst, 1987). Most of these problems appear because a stranger is expected to behave "like a native" by host people. According to Pearce and Kang "'acting like a native' consists of being perceived by natives as using the cultural resources that contain the 'moral order' of 'language games' that are 'intended' by particular acts" (1987, p. 27).

In the same vein, Edmund and Christine Glenn point out in their book, Man and Mankind (1982), that "communication among men is made possible by their having something in common; it is made difficult by the differences which exist among them" (p. l). This means that, in order to act as the host people do, foreign people first have to share the frame of reference of their hosts. The foreigner must learn 
the hosts' frame of reference. Detecting the similarities and differences is the hardest part of such a process.

Glenn and Glenn continue: "People whose experiences are similar...can communicate with ease and in depth. Sharing experiences is easiest for. . those belonging to the same social group" (p. 32). So, when people hold different values, those different values account for the differences in communication patterns held by the participants in any given encounter. Moving to another culture means that to a certain extent one's own behavior, rules and accustomed ways for dealing with everyday activities do not work effectively anymore. In other words, "as foreign immigrants move from one culture to another, behavioral modes and values in the old setting may prove maladaptive in the new" (Kim, 1977, p.66). To the extent that old ways of behaving do not function in the new setting, the stranger will have to learn the roles, behaviors, values and the majority of the elements that constitute the new culture.

To sojourners, one of the main causes of the frustration and feeling of disorientation that they may experience during their sojourn is the fact that they have to learn those unfamiliar ways of living in the new environment. The literature confirms that the learning process leads to adjustment that is an anxiety-producing. The sojourner encounters a period of uncertainty and 
anxiety, that, according to several authors, decreases when, again, the environment begins to make sense to the visitor (e.g., Gudykunst and Hammer, 1987 and Lewis and Jungman, 1986).

There are different levels of adjustment and those levels relate to whether the stranger wants to remain in the host country, and what his/her goals are. Brislin (1984), quoting Taft (1977), writes: "A complete adjustment is marked by four developments which involve peoples' beliefs, attitudes, values, and behaviors: cultural adjustment, identification, cultural competence, and role enculturation . . " (p. 282).

Brislin relates cultural adjustment fundamentally with the stranger's sensation of being "at home". Identification refers to the feelings of belonging; foreigners positive in the knowledge that they are going to return home are able to adjust without necessarily identifying. As Brislin put it, "they can feel comfortable and at home without concluding that the host country is where they belong" ( $p .284$ ).

By cultural competence it is meant that the sojourner is able to function well in a variety of interactions with host people. At this level, language skills and knowledge about the culture have improved. All strangers, regardless of whether they are planning to stay or to go back home, have to achieve cultural competence in order to adjust. 
According to Brislin (1984), cultural adjustment, identification and cultural competence are mandatory for all long-term sojourners.

The last stage, role acculturation, is described as one in which "there is an increasing sense of convergence between one's own attitude and values and those held by a large number of host" (Brislin, 1984, p. 286). This level is reached after living in the host culture for a long period of time. At this point, the visitor does not behave in certain ways because he or she has to, but because he wants to. There is no conflict of values present at this level, as there is in the former levels.

\section{Culture shock}

Culture shock, also known as role shock (Byrnes,1966), culture fatigue (Guthrie, 1975), or culture stress (Barna, 1985) has been a concept used to explain the adjustment problems of a sojourner. Several authors have defined the term. Following are some of the authors that have discussed this concept, and a few of the many definitions of culture shock. Oberg (1960), who is the first author who defined the term, places primary emphasis, on the negative aspects of culture shock by labeling it as an ailment, while Adler (1975) points out the positive effects of culture shock as a tool to improve self-development and personal growth. More recently, Bennett (1977) talks about culture shock as one subcategory of "transition shock," 
which she defines as "a state of loss and disorientation precipitated by a change in one's familiar environment which requires adjustment" (p. 46).

In some of the literature, culture shock is conceived as an adjustment process in itself, with its own stages, such as contact, disintegration, reintegration, autonomy and independence (Adler, 1975). In Bennett's article, the stages are referred as fight, flight, filter and flex (1977). Other authors (e.g., Gullahorn and Gullahorn, 1963; Kohls, 1984; and Lewis and Jungman, 1986) regard culture shock as just one phase of the entire process of adjustment and this is reflected mainly in some of the curves of adjustment that are described in the following section.

Curves of Adjustment and Graph of Emotional Intensity

The adjustment process seems to follow a pattern, even though not all sojourners have the same reactions when encountering new cultures. The general form of this trend has been recognized as a curvilinear one (Gullahorn and Gullahorn, 1963; Kohls, 1984; and Lysgaard, 1955). A common characteristic of the different curves of adjustment is that each is designed to explain the reactions of adjustment over a period of time. In other words, the experience of overseas adjustment has a temporal connotation, to the extent that a sojourner's ability to adapt to the new environment varies as time goes by. 
The discussion about the U-Curve Hypothesis (refer to Figure 1) developed by Lysgaard (1955) is that there is an initial period of well-being: the so-called spectator phase. Following this phase is a period--the involvement phase--during which feelings of depression, apprehension and anxiety occur.

At this point, the stranger begins to understand the new culture (coming-to-terms phase) and in so doing the curve starts an ascending process, indicating an improvement in the sojourner's negative feelings. The U-Curve ends with a new period of well-being, termed pre-departure (Kahne, 1976). The W-Shaped Curve (Gullahorn and Gullahorn, 1963), (see Figure 2) known as the extension of the U-Curve Hypothesis, "extends beyond the U-curve to describe a re-adjustment period when the visitor returns home again, which is somewhat like the experiences he may have had during the initial involvement and coming-to-terms phases during the visit" (Lundstedt, 1963, pp. 5-6). Kohls (1984) argues that there are four stages of personal adjustment. These stages are: initial euphoria, irritability and hostility, gradual adjustment and adaptation, and biculturalism. In addition, Kohls includes the reverse culture shock experience that the Gullahorns add to the U-Shaped curve. Kohls suggests "that there are not one but two low points" (1984, p. 68) in the curve 


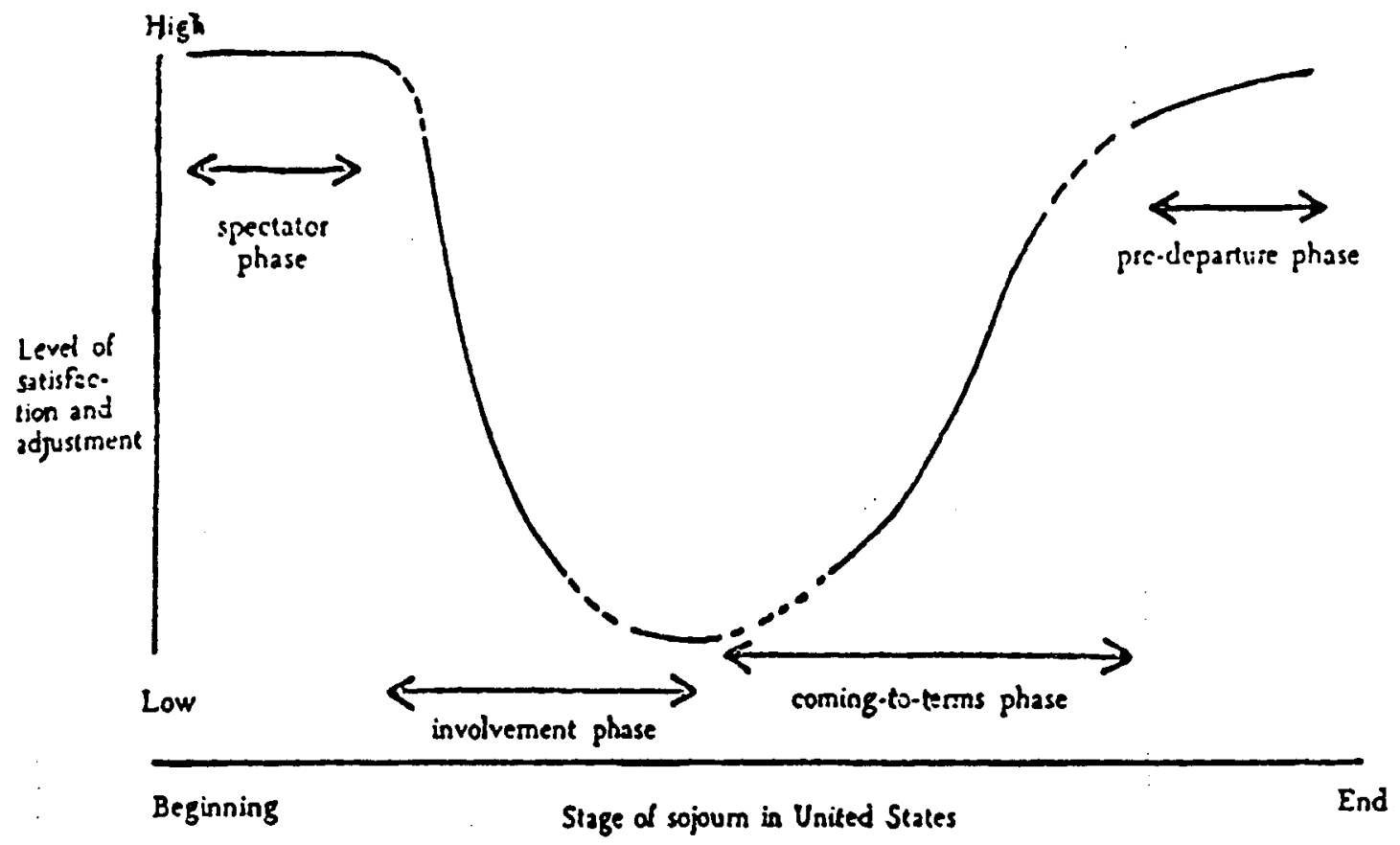

Figure 1. U-shaped curve of adjustment. Source: Sven Lundstedt, 1963:5. 


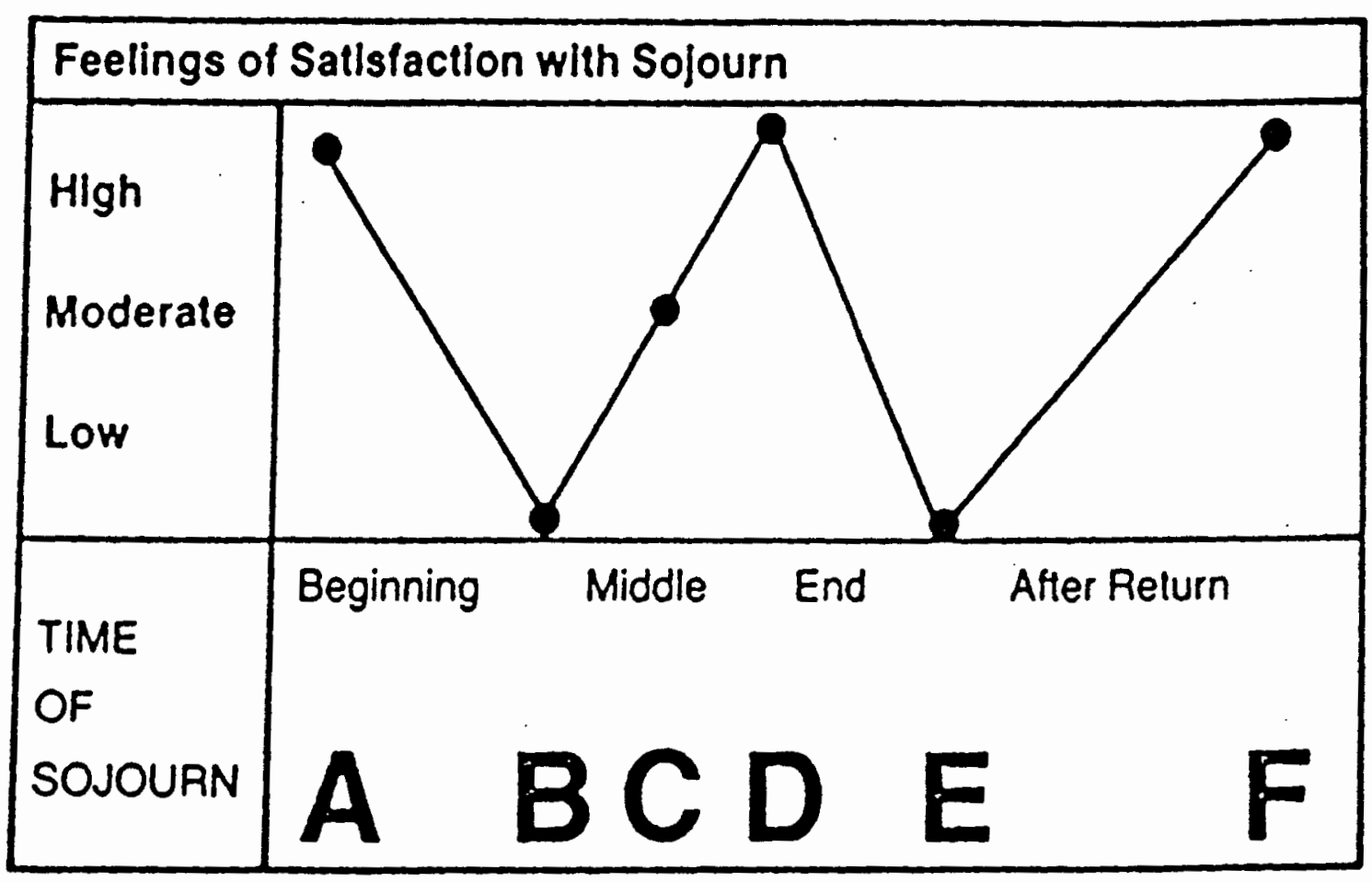

Figure 2. W-shaped curve of adjustment. Source:

Tom J. and Robert E. Jungman, 1986: xix. 
during the sojourn (see Figure 3). Furthermore, kohls asserts that these two low points have the intriguing characteristic that "they will accommodate themselves to the amount of time you intend to spend in the host country" (p. 68$)$.

The latest form used to describe the adjustment process is not a curve. It is a graph known as the Graph of Emotional Intensity (Lewis and Jungman, 1986). (Refer to Figure 4). To all the phases included in the above-mentioned curves, this graph adds a new one: the pre-arrival phase. The Graph of Emotional Intensity shows the variety of emotional levels that a stranger may experience during his or her sojourn in a culture different than his or her own. The graph is based on a temporal dimension and is subdivided into six phases.

The first phase is called the Preliminary Phase. At this stage, people are still at home, experiencing a normal level of emotions. As they prepare themselves to leave home, they experience a mixture of feelings ranging from excitement about going to another country to regret about leaving their home country.

Expectator Phase occurs when the sojourner arrives in the new culture. He or she starts to look around. Everything seems easy, exciting, just like home. Excitement is the most noticeable emotion experienced by people in this stage. At the end of this phase, people 


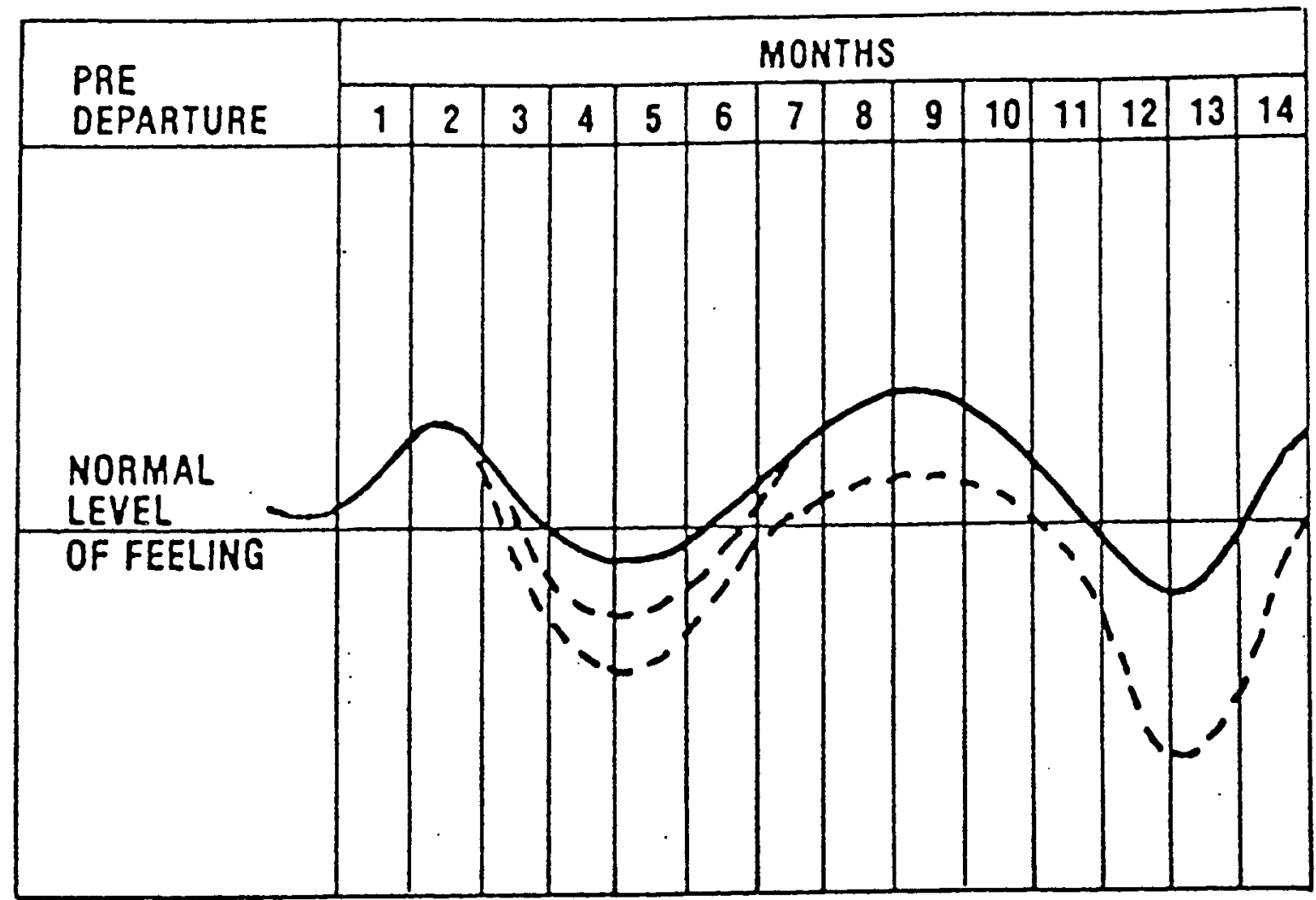

BROKEN LINES INOICATE THE EXTAEME IN SEVERITY WITH WHICH CULTURE SHOCK.MAY ATTACK.

Fiqure 3. Culture Shock Cycle. Source: Robert Kohls, $1984: 68$. 


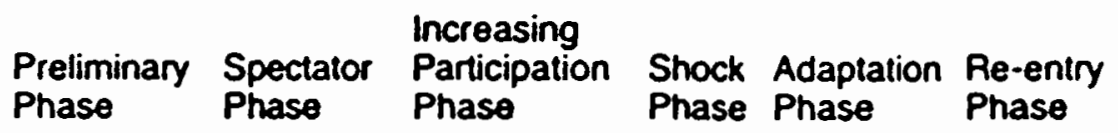

Highly Excited

Level Phase Phase

Participation Shock Adaptation Re-entry

1

Normal Intensity
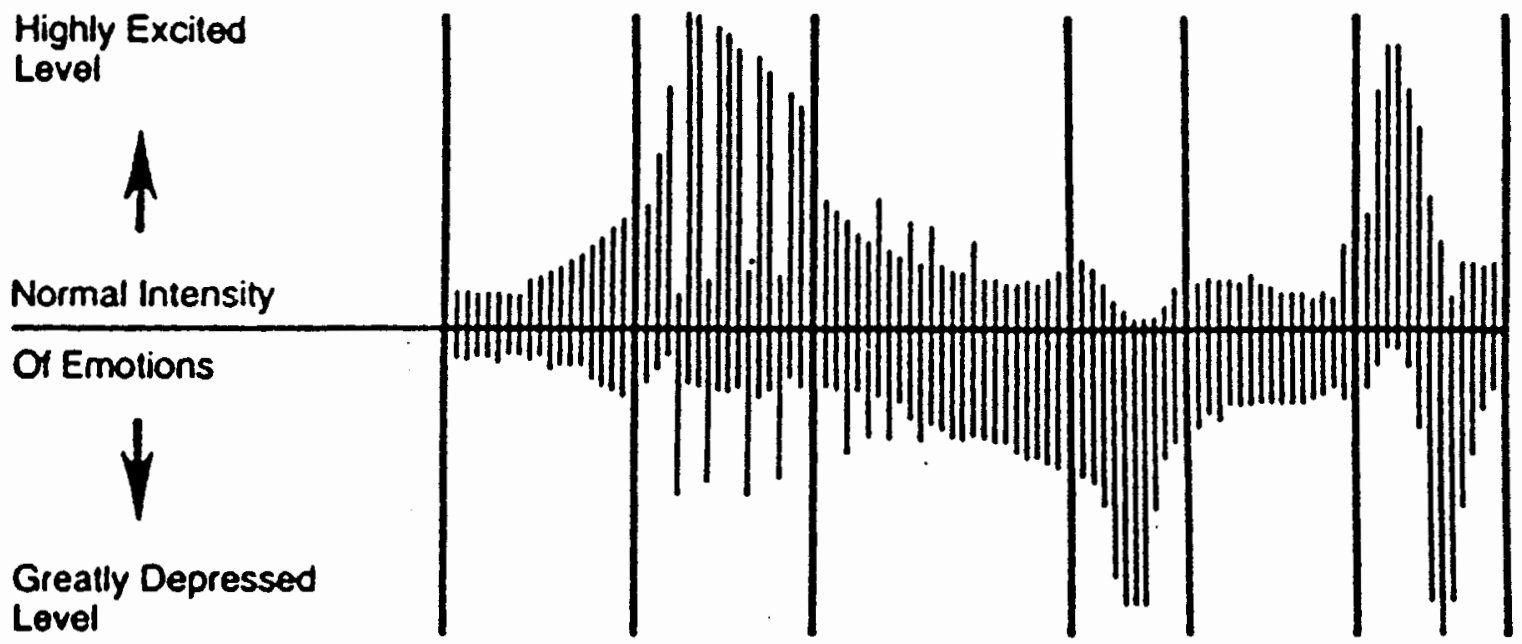

Figure 4. A graph of Emotional Intensity. Source: Tom J. Lewis and Robert E. Jungman, 1986:xx. 
tend to participate rather than just observe. In some way, the stranger begins to feel a little uncomfortable. During the third phase--the Increasing Participation Phase--foreigners exchange their mainly passive attitude for a more active one. Because of that, this is a phase characterized by "a clash of cultures, a conflict between one's own culture-based behaviors and values and those of the host culture" (Lewis and Jungman, 1986, p. xxi). People react in various ways to this phase. Some become resistant to adaptation while others, more tolerant of the new cultural patterns, react with more flexible attitudes. In any case, toward the end of this phase sojourners enter a state of confusion, wherein they feel frightened when they realize that they are becoming closer to the new culture and further from their own. What they are experiencing is known as an identity crisis (Lewis and Jungman, 1986).

This behavior constitutes the first effort at adaptation, but in attempting to adapt, strangers face a period of deep crisis of personality and/or depression. In the Shock Phase--the fourth phase of the process--they go through a difficult time and suffer from recognizable symptoms which may include loneliness, excessive cleanliness, sleepiness, drinking disorders, eating problems, and irritability. 
After the Shock Phase comes the Adaptation Phase, which "is the end point of the experience of being foreign, the point at which the sense of foreigness no longer exists" (p. xxii). In this phase, people are not only comfortable within the visiting culture but they also feel part of it. At a certain point in their sojourn, foreigners start feeling " 'at home,' comfortable, and able to meet day-to-day problems with efficiency" (Brislin, 1984, p. 280). Then later, as the sojourner spends more time in the host culture, he or she develops "a feeling of belonging" (p. 124), which Lewis and Jungman describe as "a sense of being not only in it [host culture] but of it as well" (1986, p. xxiii).

The sixth and last part of this graph is the Re-entry Phase. This phase is the process of adjustment experienced again back in the sojourner's homeland. All of the five states described above are experienced one more time. In this phase, people have to adjust to their own culture and re-learn the norms, values, beliefs, behaviors and in general the communication patterns of the home culture (Lewis and Jungman, 1986).

As it is in the case of the curves, this graph is not meant to be an exact representation of what everyone would experience when traveling to a different culture. Although the experience varies according to the person and the culture, this graph shows a pattern that could be the norm 
for a large group of people and can be used to explain the cultural adjustment process that strangers go through when they visit another culture.

Other theories

In addition to culture shock, the curves and graph of adjustment aforementioned, there are several other theories used to explain the cross-cultural adjustment process. Among them are: personality typologies and traits (Brislin, 1984); social interactions (Brein and David, 1971); tour satisfaction (Gudykunst, Wiseman and Hammer, 1977); reinforcement theory (David, 1972); and appropriate expectations hypothesis (Furnham and Bochner, 1986).

To include some examples, Brislin (1984), for instance, discusses personality traits as aspects which play a substantial role in adaptation to a foreign culture. Among personality traits are: tolerance for ambiguity, ability to relate with other people, and positive self-esteem. Another example could be the appropriate expectations hypothesis. Concerning this theory its main assumption is "that the relationship between a sojourner's expectations of the chosen country and the fulfillment of those expectations is a crucial factor in determining adjustment" (Weissman and Furnham, 1987, p. 315).

Pertaining to social interactions Brein and David (1971), quoted by Benson (1970), compare "'overseas adjustment with effective interpersonal functioning,' and 
feel that . - it is a necessary condition for adaptation" (p. 23). Additionally, other aspects that could be used as measures in defining adjustment are listed by

Benson as follows: Language skills; communication skills; interaction (with hosts); reinforcing activities; friendliness; socially appropriate behaviors; job performance; attitudes; satisfaction and mobility.

\section{GENERAL ADJUSTMENT PROBLEMS}

Brislin (1984) notes that some years ago it was widely accepted that only people who suffer social adjustment problems in their own society would encounter difficulties when traveling to another culture. Today, it is accepted that almost everyone may experience adjustment problems to one degree or another. He also says that "the major assumption behind any discussion of cross-cultural adjustment is that difficulties which demand coping responses are normal and expected" (p. 277).

Brislin states that foreigners who leave their countries and have to adjust to a new culture face not only the common difficulties that moving implies, but all the extra demands that living in a different culture bring about. He classifies those difficulties as either short-term or long-term.

Short-term difficulties are the typical problems of settling in a different environment, such as locating housing, grocery stores, hospitals, transportation and so 
on. This author explains that none of these are big issues, but that they may become troublesome to the extent that the sojourners have to handle all of them simultaneously with the expected anxiety and stress as a result. Regardless of the length of sojourn, most visitors are likely to experience short-term adjustment difficulties (Brislin, 1984), which can be considered as the unavoidable first steps that must be taken in order to achieve the main purpose(s) of the sojourner's visit.

Strangers are expected to encounter other sorts of problems along the way, until they become adjusted to the new cultural environment. These long-term adjustment problems (Brislin, 1984) are mainly intercultural communication problems.

In adjusting to another culture, foreigners encounter obstacles when trying to communicate with hosts. Barna (1985), labels these barriers "stumbling blocks in intercultural communication," and has identified six: assumption of similarity, language, nonverbal misinterpretations, preconceptions and stereotypes, tendency to evaluate and high anxiety.

The first one, assumption of similarity, is related to the generalized belief that everyone is the same: because people speak the language, or dress in alike fashion it is assumed that they behave and think in the same manner. This attitude can present a very real problem for 
sojourners as they attempt to adjust. It will affect communication and, therefore, adjustment in many ways.

Language is perhaps the more obvious impediment to adjustment. People need to verbalize their needs and their feelings. They need the language skills necessary to facilitate everyday life. Strangers must learn the language of the host country. Otherwise, language will turn out to be a significant barrier to adjustment. Kim (1977) also emphasizes the importance of language. He says: "It is postulated that an immigrant's competence in speaking and understanding English facilitates. . . his interpersonal interaction with Americans . . " (p. 69). In addition, DuBois (1956) points out that language is of fundamental relevance due to the fact that it influences to a high degree the foreign students' facility in communicating, which determines his/her academic success and contributes to make his/her relationships satisfactory.

In regards to nonverbal misinterpretations, Barna states that "the lack of comprehension of nonverbal signs and symbols that are easy to observe--such as gestures, postures, and other body movements--is a definitive communication barrier" (1985, p. 334). She also includes use of time, use of space and attitudes toward formality as types of nonverbal codes.

Preconceptions and stereotypes are considered to be another major problem in intercultural communication 
because "they interfere with objective viewing of stimuli - ." (p. 334). Visitors use these preconceived notions in order to explain the world around them, which otherwise would make no sense to them. Several authors (Barna, 1985; Becker, 1962; and Brislin, 1984) argue that generalizations are useful because they help the sojourner to understand the unknown but, when overused, become a "reality" placing the stranger far away from the real world.

The tendency to evaluate constitutes a stumbling block to the extent that when sojourners apply their own frame of reference to categorize an attitude or behavior present in the host culture as appropriate or good, they are limiting their ability to appreciate those behaviors in terms of the natives' point of view. Thus, the tendency to evaluate will be a powerful impediment for cultural learning. Finally, Barna (1985) mentions that high anxiety relates to all the previously mentioned stumbling blocks. As indicated elsewhere in this thesis, stress is a common feeling when people confront the unknown and when the predictable world turns unpredictable. Thus, anxiety is inherent to international experiences. When not appropriately dealt with, anxiety negatively influences the outcomes of intercultural encounters. 


\section{ADJUSTMENT PROBLEMS OF FOREIGN STUDENTS}

The assumption of this thesis is that even though students everywhere face similar problems, students in countries other than their own will encounter additional problems. Even difficulties such as academic stress and housing or finances that are shared by hosts and foreign students alike must be seen in a different perspective in the case of foreign students.

There is disagreement in the literature as to whether the problems of adjustment faced by foreign students are the same as the problems of any student anywhere in the world. Typical of one position is Dixon C. Johnson (1971), Director of International Students Affairs at the University of Tennessee, who conducted a survey among foreign students, and concluded that the problems of foreign students are almost the same problems faced by local counterparts. In brief, Johnson maintains that foreign students are more students than foreigners, and must be treated like that for their own sake. He implies that it would be better for foreign students to be treated as any other student and not as something peculiar, which makes everything difficult for them.

In addition, Golden (1971), who offers a psychiatrist's view regarding foreign students' adjustment, suggests that the problems faced by them include the usual difficulties of students in any given society. Golden 
explains this by saying that "the same tasks of establishing self-esteem, meaningful interpersonal relationships as a means to self-esteem, and identity in terms of career goals are common to all adolescents of university age" (p. 34). Nonetheless, in stating that "obviously, the social isolation of being a stranger, with temporarily limited communication skills, aggravates the problem further" (p. 34), he acknowledges that the problems are different in some way or that additional problems are manifested in the case of students abroad.

on the other hand, there are more authors (e.g., Deutsch \& Won, 1963; Pruitt, 1978; Schild, 1968; and Sharma, 1971) who suggest that the problems faced by foreign students are different from the problems encountered by students from the host culture. Among the problems 1 isted by the above-mentioned authors are homesickness and isolation, not having satisfactory social interaction with host nationals, speaking a different language, and having different values.

Other authors (Furnham and Bochner, 1982) support the idea that foreign students--in addition to the normal problems of any student--deal with troublesome areas not shared by anyone else but another foreign student. Four categories of such problems have been proposed by Furnham and Bochner: general adjustment problems of foreign people (language ability; separation; housing; loneliness, etc.); 
problems of young people (building up independence, self-esteem, becoming a good citizen, etc.); academic stress (difficulties in coping with the responsibilities of being a student); and the role of being an ambassador for one's country. According to Furnham and Bochner the first and fourth categories are unique to foreign students while the second and the third are considered to be common for nationals as well as visitors.

Further support for the position that foreign students and host students face different problems can be found in the conclusion of the John Wilson Porter's doctoral dissertation entitled "The Development of an Inventory to Determine the Problems of Foreign Students" (1962). One of the purposes of Porter's research was to determine to what extent the problems of foreign students could be similar to the problems of American students. To accomplish this goal, he administered the Michigan International Student Problem Inventory to foreign students as well as to U.S. students. One of the conclusions of this study was that the inventory provided evidence that not all problems are the same for foreign students and American students. Furnham and Bochner assert that there is a set of adjustment problems that relates to all sojourners, including foreign students. In his article, "The Adjustment of Sojourners," Furnham states that "there are problems that confront anybody living in a foreign culture, 
such as racial discrimination, language problems, accommodation difficulties, separation reactions, dietary restrictions, financial stress, misunderstandings, and loneliness" (1987, p. 52).

It is widely acknowledged in the literature that foreign students look for more meaningful relationships, which suggests that the superficiality of friendships and the weakness of family ties present in the American society become a problem in terms of adjusting to this culture (e.g., Selltiz and Cook, 1962). Regarding this issue, Stewart (1969) comments that

- - the foreign student may miss the resilience and commitment in human relations to which he is accustomed. He finds it easy to be included in social and academic groups but difficult to be accepted into the inner circles. In many cases he may be searching for an intimacy and closeness in social relations which is largely absent from American social and academic life. (p. 2)

Two significant elements of adjustment are reported as a result of a study conducted by Deutsch and Won (1963): language facility and frequent social contact with Americans. The findings show that when either of these aspects are part of the sojourner's experience the sojourner makes a better adjustment to his or her new environment.

Several authors have discussed the role that the stranger's social interaction with host people plays in the adjustment of the former. Deutsch and Won (1962) have used social contact of foreigners with Americans as a measure of 
the adjustment of sojourners to American culture. The results of their study show that, in fact, there is a positive relationship between these two factors. Research about adjustment of African students to the American society (Pruitt, 1978) emphasizes the positive influence of interaction between Africans and Americans in improving the adjustment of the African students. Maladjustment was the norm in Africans who had more contact with their own countrymen. Referring to the influence that interaction between visitors and host people has on the adjustment of the former, Benson (1978) points out that "it has been shown that foreign students who interact more with host country individuals tend to be more satisfied with their overseas experience" (p. 23).

In addition, Brislin (1984) mentions an analysis made by Benson (1978) about Peace Corp volunteers in Brazil, in which it is clear that Americans who interacted more with natives seemed to adjust better. Gudykunst and Hammer (1987) also say that "research on adjustment . . . suggests that developing intimate relationships . . with host nationals facilitates the adjustment of strangers . . ." (p. 123). Brislin (1984), and Sermol (1983), argue that this occurs because, even though people need a support group in order to adjust to another culture, these support groups could delay the adjustment process that sojourners 
have to go through when living in a culture different from their own.

Sermol uses terms such as intra-ethnic communication and inter-ethnic communication to explain the types of interaction that a sojourner might have in another country. Intra-ethnic communication relates to communication of sojourner with countrymen, while inter-ethnic communication refers to communicative acts between the stranger and the group of host people. According to Sermol, the point here is that the stranger needs both intra and inter-ethnic communication to feel better in the host society. Sermol also suggests that intra-ethnic communication is helpful at the beginning of the stay, but could be harmful when over-used. After an initial period of newness in the host culture, the stranger should shift from more intra-ethnic to more inter-ethnic communication. In sum, it seems that foreign students have to have more contact with host nationals than with countrymen in order to adjust.

More adjustment problems of foreign students are listed in the literature. Spaulding et al. (1976), for instance, enumerate them as follows:

1. Understanding lectures

2. Reciting in class

3. Adapting socially on campus

4. Being isolated from the mainstream

5. Feeling lonely and unwelcome

6. Perceiving Americans to be cold, lacking familiarity with other cultures (p. 48). 
Other adjustment problems of foreign students are Iisted in Sharma's (1971) research, a study that identifies the adjustment difficulties of foreign students using an inventory of problems. The sample for the study consisted of foreign non-European graduate students, including people from the Ear East, South Asia, Middle East, Africa and Latin America.

After applying her "Foreign Students Problems Inventory" (1971), Sharma reports the most drastic problems, as related by the students, and classifies them in three main areas: academic problems; personal problems; and social problems. Sharma concludes that among the academic problems are "giving oral reports, participating in class discussions, taking notes in class, understanding lectures, taking appropriate courses of study, and preparing written reports" (1971, p. 155).

The most intense personal problems relate to "home sickness, adequate housing, enough funds, food, and finding companionship with the opposite sex" (p. 155). Finally, regarding social problems, Sharma mentions the following as the more severe ones: "becoming used to American social customs, making personal friends with American students, being accepted by the social groups, and inhibited participation in campus activities" (p. 155).

Adjustment problems in general, and the particular problems faced by foreign students, have been covered in 
the two previous sections. Although these general and particular problems may be expected to be the same as those Costa Ricans might experience, specific cultural differences between Costa Ricans and other foreign students, as well as Costa Ricans and American students, introduce a new variable.

The problem of a Costa Rican student may be the same general category of problem that another foreign student faces. But, inherent cultural value systems surrounding that problem vary enourmously from culture to culture. In effect, a Costa Rican student's difficulties with friendship, for example, are not the same as the difficulties experienced by a Chinese student whose culture may view friendship differently. For a third foreign student, friendship may not be problematic because his/her particular cultural values more closely align with those values of Americans. Authors cited later in this thesis have concluded that in fact, American and Costa Rican value systems differ in many significant respects.

Thus, the primary factor, surrounding adjustment problems, to be examined in this thesis, and the one mentioned last here for emphasis, is the value conflict that may arise from differences in value systems between the Costa Rican and American cultures. This issue will be discussed in depth in the next section. 


\section{VALUE SYSTEMS AND THE ADJUSTMENT PROCESS}

The preceding discussion has highlighted the fact that foreigners have to face many problems when they live in another culture. Among these problems are language problems, accommodation difficulties, separation reactions, financial stress, loneliness, and academic issues. But, the main assumption of this thesis is that in addition to all these problems, foreign students encounter other culturally based problems.

Also, as cited elsewhere in this study, it has been widely accepted that strangers sojourning to other countries are likely to face cultural differences that cause conflict. More and deeper problems arise when one's values confront those of the host country.

With respect to this matter, Mestenhauser (1969)

states: "the conflicts which arise require 'adjustments' of the individual when he rejects, accepts, synthesizes, or compartmentalizes his previously held values from the new ones" (p. 1).

In their book, An Introduction to Intercultural

Communication, Condon and Yousef (1987) extensively discuss four main aspects in the area of cultural problems. These four aspects, which differ from culture to culture, are: cultural values; nonverbal behavior; language behavior; and patterns of reasoning and rhetorical expression. 
According to Furnham (1987), "the differences in values. . that exist among many cultures have been used to account for the misunderstandings, distress, and difficulties experienced by cross-cultural sojourners" (p. 56). There are references in the literature (Condon and Yousef, 1987; Kohls, 1984; Tyler, 1987, for instance) to the shock experienced by foreign students when the rules of behavior and beliefs of their own culture confront those of the new culture.

The value system approach, initially stated by Kluckhohn and Strodtbeck (1961) and later expanded by authors such as Condon and Yousef (1975) and Kohls (1987), suggests that communication breakdowns are basically a result of cultural differences in values. This approach consists of the analysis of the value orientations that rule the way in which different people perceive or conceptualize different aspects of their experience as human beings.

Thus, based upon the previous statements, the main assumption of this thesis is that intercultural communication problems arise fundamentally from the differences in value systems. This thesis is concerned specifically with two sets of value orientations: North American and Latin American. The latter is a generalization of a culture that includes the Costa Rican culture. The specific model that is going to be the 
theoretical support in reference to values is the Comparative Model for comparing cultures, also known as the Kohls' Model (refer to Figure 5).

Based on the following discussion, the value orientations contained in the right column are going to be considered as the predominant values of the Latin Americanculture, with one exception. Support for these assumptions is taken mainly from Condon (1985), whyte and Holmberg (1956). In order to be as accurate as possible, it is necessary to substitute the Past orientation for the Present Orientation, because the latter is more common in Latin American societies. This researcher supports this change based on her personal experience as an individual primarily socialized in a Latin American country. With regard to the American value system, several authors have described the main values that function in the American society (Lainer, 1981; Kohls, 1984; Stewart, 1985; Condon and Yousef, 1987; Tyler, 1987 and Althen, 1988). Among these values are: individualism, privacy, competition, future orientation, doing orientation, and materialism.

On the other hand, Condon (1985), the author of an article and a book about the Mexican culture, discusses some aspects of the value system of the Latin American culture. Based on these readings, the values that best 
SOME OTHER COUNTRY'S

VALUES

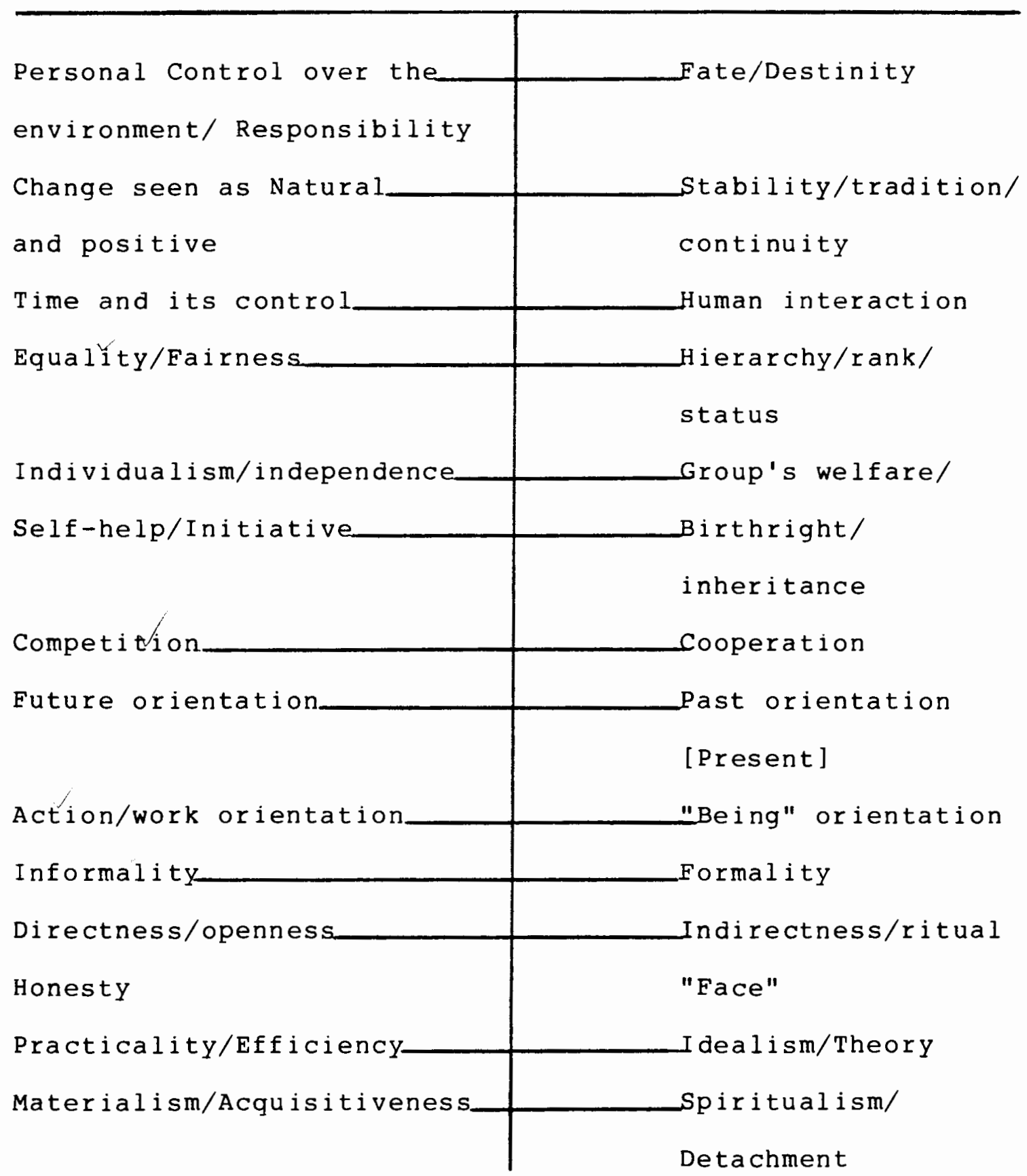

Eigure 5. Kohls' Comparative Model. Source: Robert Kohls, 1987:20. 
describe the Latin American culture are group orientation, cooperation, present orientation, human orientation, being attitude, and spiritualism.

Also, the literature reviewed includes a few books regarding Costa Ricans. Barahona (1975), Biesanz et al. (1982), Lascaris (1977) and Lundberg (1960) relate in their books some general aspects of the Costa Rican society, as well as behaviors or beliefs commonly held by the costa Rican people. Specific aspects of nonverbal communication present in the interaction behavior of Costa Ricans, such as proxemics and tactility, are discussed by Edward Hall (1959) and Robert Shuter (1976).

Some of the mentioned value orientations are going to be discussed, here, in more detail. The meaning of the American and Latin American value orientations will be presented simultaneously.

Individualism is a dominant value orientation of the American culture. Many authors have discussed this issue (e.g. Althen, 1988; Condon and Yousef, 1987; DuBois, 1956; Gudykunst and Ting-Toomey, 1988; Stewart, 1985). First of all, when discussing this value orientation, Kluckhohn and Strodtbeck (196l), and more recent authors (e.g., Condon and Yousef, 1987), mention the difference between individualism and individuality.

Kluckhohn and Strodbeck assert that individualism encourages each person to ". - decide for himself, 
develop his own opinions, solve his own problems, have his own things and, in general, learn to view the world from the point of view of the self" (1961, p. 7ø), while individuality--operating within a culture where a person's first obligation is to the norms of family and tradition-is allowed to develop only as it does not interfere with those primary norms.

In his book, Good Neighbors, Condon (1985) argues that at first glance, Americans and Mexicans seem to agree about the importance of the individual in the society, but in a second look one will be able to recognize that what each culture means is completely different. Condon says that while North Americans talk about "individualism," Mexicans are talking about "individuality." According to Condon and Yousef (1987):

What marks individualism in the United States is not so much the peculiar characteristics of each person but the sense each person has of having a separate but equal place in society... This fusion of individualism and equality is so valued and so basic that many Americans $f$ ind it most difficult to relate to contrasting values in other cultures where interdependence, complementary relationships, valued differences in age and sex greatly determine a person's sense of self. (p. 65)

Individuality, on the other hand, gives an individual the opportunity of being different but within the constraints indicated by the social context. Condon (1985) emphasizes that:

In Mexico it is the uniqueness of the individual which is valued, a quality which is 
assumed to reside within each person and which is not necessarily evident through actions or achievement - . That inner quality which represents the dignity of each person must be protected at all costs... ( pp. 18-19)

Costa Rican authors such as Barahona (1975) and Lascaris (1977) emphasize that Costa Rican people are very individualistic, that they love individual freedom and have a tendency to respect each other as unique persons. The Biesanz (1982), the American anthropologists and authors of a book entitled The Costa Ricans, say about the fundamental characteristics of the Costa Rican culture, that ". . freedom and individualism are highly valued... (and Costa Ricans) like to think of themselves as individuals - ." (p. 10). However, as explained earlier, this individualism has to be understood as individuality. The correlation here is that individualism is a dominant value orientation in individualistic cultures while individuality is proper of group-oriented cultures or collectivistic cultures. Gudykunst and Ting-Toomey (1988) argue that members of the latter

perceive ingroup relationships to be more intimate than members of individualistic cultures. Ingroup relationships include brother/sister (family ingroup), coworker and colleague (company ingroup), and classmate (university ingroup) . . . (p. 42)

The just mentioned ideas about ingroup relationships lead to another orientation: How the concept of "family" is defined in each culture. Again, several authors (e.g., Clarke and Ozawa, 1970; Condon and Yousef, 1987; and White 
and Holmberg (1956) discuss what is meant by family in the u.s. culture. A typical definition of the American family concept is offered by Althen:

When Americans use the term "family," they are usually referring to a father, a mother, and their children. This is the so-called 'nuclear family.' Grandparents, aunts, uncles, cousins, and other who might be labeled 'family' in many other countries are 'relatives' in American terminology - . for most Americans, the family is a small group of people, not an extended network. (1988, p. 48 ).

White and Holmberg, in contrast, describe the concept of family in Latin America as playing ". . a more significant role in the patterning of human relations than they do in the United States" (1956, p. 6). Referring to the Costa Rican culture the Biesanzs remark that "foreign observers note that family ties are still strong and extend to a large circle of relatives" (1982, p. 88). The Latin American concept of the family is also touched upon by Condon (1985), who describes the Mexican family, and Barahona (1975) who talks about the Costa Rican family, specifically.

There are two additional contrasting characteristics between the American and the Latin American families. One is that while in the U.S. "in the stereotypic 'average family,' the children are ready to move out of the parents' house by the age of $18--$ that is, when they have completed secondary school" (Althen, 1988, p. 51), in Mexico the children are not expected to do so (Condon, 1985). 
In Mexico, as it is in Costa Rica, "the children, when they become mature, separate from their parents to establish a new family . . " (Barahona, 1975, p. 68) (translated by this reseacher). Children leave their parents' home only when they get married, and according to Barahona even then that is not a complete separation, as they characteristically live close to their parents and seek their advice.

The second contrasting characteristic is that although in the U.S. "even the grandparents are expected to live apart from their children and grandchildren . . in Latin America, - . it is taken for granted that old people will live with their children" (White and Holmberg, 1956, pp. $7-8)$

There is a strong relationship between the individual and the family in the Latin American societies. Two examples follow: "a Mexican will most often regard himself first of all as a part of a family . . (Condon, 1985, p. 19), and "most Ticos (Costa Ricans) are oriented primarily to their families. . " (Biesanz, et al., 1982, p. 11$)$

Another contrasting value orientation between the American and Latin American cultures is the orientation to action. There are several authors who discussed this "doing" American attitude first stated by Kluckhohn and 
Strodtbeck (1961). Among them are Condon and Yousef (1987), DuBois (1956), Gudykunst and Ting-Toomey (1988), Harris and Moran (1987), Kohls (1984), and Stewart (1985). According to Condon and Yousef (1987) "the dominant activity orientation in North America is still, apparently, one of doing . . " (p. 137) while "the dominant activity orientation in Latin America as a whole is likely to be one of being (p. 137).

Concerning the traits of the American action orientation, Stewart (1985) states: "The foreign visitor in the United States quickly gains an impression of life lived at a fast pace and of people incessantly active. This image reflects that doing is the dominant activity for Americans" (p. 36). In addition, Stewart points out that "doing...emphasizes visible and measurable actions" (p. 37). Regarding this issue, another author comments "more generally, Americans like action.. . They tend to believe they should be doing something most of the time" (Althen, 1988, p. 16).

The Latin American being orientation has been dicussed by Gudykunst and Ting-Toomey (1988), Kluckhohn and Strodtbeck (1961), Kohls (1984), and Lascaris (1977). In regards to being orientation, Kohls' reproduction of the Kluckhohn and Strodtbeck's model reads: "It is enough to just "Be." It's not necessary to accomplish great things 
in life to feel your life has been worthwhile" (1984, p. 85$)$.

Gudykunst and Ting-Toomey refer to this matter in the following words:

In the being orientation, the kinds of activities that are performed are 'spontaneous expressions of what are conceived to be givens in the human personality' (Kluckhohn and Strodtbeck, 1961, p. 16). An excellent example is the Mexican fiesta, which, according to kluckhohn and Strodtbeck, reveals "pure" impulse gratification. $(1988, \mathrm{p} .51)$

Lascaris (1977) more precisely describes the Costa Ricans' action orientation with one word, "pasandola" (p. 134). This researcher could not come up with an equivalent English word, but the closest meaning could be "just being." Lascaris further explains that Costa Ricans possess "a contemplative sense of existence, intensively experiencing the present, without anxiety related to time pressure" (1977, p. 134) (translated by this researcher). Friendship is also conceived differently in each culture. Here, as in individualism versus individuality concepts, it seems that a distinction has to be made between "friendship" and "friendliness." Americans are perceived as being very friendly by foreigners, "for many visitors, the American comes on too strong too soon . . " (Harris and Moran, 1987, p. 341). As Smith (1955) states it: ". . Indications of friendliness in this characteristically American version are often mistaken by the visitor as tokens of friendship, and interpreted as 
implying a degree of personal commitment that is far from intended" (p. 235).

Four factors could be used to characterize patterns of friendship: spread; duration; obligations; and mutual trust (DuBois, 1956). Hence, according to DuBois, if one is to describe the American concept of friendship in terms of those four elements "one would say that they are widespread, low in obligations, short in duration, and high in trust" (p. 62).

It is this researcher's contention that DuBois' characterization of the Japanese friendship also applies to the Latin American concept of friendship: "small in spread, high in obligation, long in duration, and high in trust" (p. 63). Referring, particularly, to the Mexican concept of friendship, DuBois goes further emphasizing that "if friendship exists, it is in terms of special relations to real (or putative) kin. This justifies obligations and overcomes the suspicion and the short-term quality of clique relationships" (p. 63).

In describing what "friendship" means to Americans, Harris and Moran say it is a "social friendship (short commitment. . .)" (p. 339). In the same vein, stewart (1985), states that the pattern of friendship in America reflects "the American reluctance to becoming deeply involved with other persons" (p. 54). In addition, Stewart mentions another trait of the American friendship. He 
says: ". - the American tends to limit friendship to an area of common interest . - The company of a friend centers around an activity, a thing, an event or a shared history" (1955, p. 54).

Contrasting the stated traits of the American concept of friendship with the Latin American one, this researcher, based on her experience as an individual primarily socialized in the costa Rican culture, would say that the Costa Rican concept of friendship involves a long-lasting, close relatioship that implies deep involvement and takes into account not aspects of an individual but the whole person.

The dichotomy of materialism versus spiritualism constitutes another relevant cultural difference between the American and Latin American societies. Materialism has been widely discussed in the intercultural communication literature as a fundamental value of the American culture. This value contrasts with the dominant spiritual goals of the Latin American culture.

In trying to describe the American culture, the authors Harris and Moran (1987) ask: "What are important goals in life?" and their brief answer to that question is "material goals" (p. 339).

Stewart offers more:

Americans consider it almost a right to be materially well off and physically comfortable. They expect swift and convenient transportation-preferably controlled by themselves--a variety 
of clean and healthful foods and comfortable homes equipped with numerous labor-saving devices, certainly including central heating and hot water. (1985, p. 64)

Althen (1988) remarks upon the criticism that Americans receive from residents of other cultures, criticism focusing on the Americans' material

acquisitiveness. "Eor Americans, though," he says "this materialism is natural and proper" (p. 16). On the other hand, Condon (1985) refers to the spiritual sense of life present in the Latin American culture, particularly in the Mexican society, in the following quotation:

- - the Mexican student considered the United states to have a materialistic society with little regard for humanistic values, for music, art, literature, or indeed any sense of the true meaning of life. . . he believed that a citizen of the United States was concerned with gaining money and material goods. (p. 9)

Condon also comments that after living in the U.S. for a while, "the Mexican student remained convinced, almost without exception, of the superiority of the Mexican life goals with their emphasis on spiritual and humanistic values" (p. 10).

There are two notions of time as it is culturally valued. One is the idea of temporal orientation, and the other is how time is used and controlled. Gudykunst and Ting-Toomey (1988), paraphrasing Kluckhohn and Strodtbeck, state that "the temporal feature of human life concerns past, present, and future orientations" (p. 52). According to Kluckhohn and Strodtbeck (1961) all three temporal 
dimensions are present in every society, but one will usually predominate. Americans' concept of the temporal orientation is "toward the future" (Stewart, 1985, p. 38) while Latin American is "part of the societies which look to the present" (p. 38).

Althen (1988), Condon and Yousef (1987), and Gudykunst and Ting-Toomey (1988) are among the authors who discuss the American's future orientation and the Latin American's present orientation. Referring to the former, Althen states:

They look ahead. They have the idea that what happens in the future is within their control, or at least subject to their influence. They believe that the mature, sensible person sets goals for the future and works systematically toward them. (1988, p. ll)

Regarding the Latin American present orientation, Condon and Yousef write:

Those cultures which may be described a predominantly valuing the present are likely to be those also characterized by the being- or being-in-becoming variations of the activity dimension. What is important is what is happening now. It is not that the future never comes but that it inevitably comes--so that manana will be the same as now. The past, too, is not denied or forgotten; more likely it is interpreted as a more distant present. (1987, pp. 109-110)

In order to explain the concept of time in terms of how it is used and controlled, Condon (1985) as well as Gudykunst and Ting-Toomey (1988) use Hall's ideas about polycronic and monochronic time. Gudykunst and Ting-Toomey explain: 
Hall (1983) differentiates between polychronic ( $P$-time) and monochronic (M-time) cultures.

Generally, people in cultures that use polychronic time do several things at once, while those in cultures that use monochronic time complete one thing before starting something else. (1988, p. 53)

In addition, Gudykunst and Ting-Toomey emphasize that

- - polychronic time stresses 'involvement of people and completion of transactions rather than adherence to present schedules' (Hall, 1983, p. 43) - Euture plans in a polychronic culture are changed as more important situations arise, [while] in monochronic cultures, in contrast, people are so attuned to time that it determines and coordinates relations with others. (p. 53)

In this sense, according to Hall, the Latin American culture is representative of the P-T while the American society is an advocate of the $M-T$. The characteristics of these two cultures can be summarize as follows:

People who follow M-time schedules tend to emphasize individual privacy, schedules, and appointments. People who follow p-time schedules, in contrast, tend to emphasize human connectedness, fluidity, and flextime. (Gudykunst and Ting-Toomey, $1988, \mathrm{p} .129)$

Also, intimately related to this topic is the social relations issue. In his model Kohls contrasts the American orientation toward time and its control with the human orientation value manifest in other cultures. This cultural difference regarding how time is valued seems to be evidenced in Gudykunst and Ting-Toomey's words: "While individualistic cultures are time-oriented, collectivistic cultures are relationaliy oriented" (1988, p. 129). 
In regards to Americans, Althen (1988) states:

In their effort to use time wisely, Americans are sometimes seen by foreign visitors as automatons, unhuman creatures who are so tied to their clocks and their schedules that they cannot participate

in or enjoy the human interactions that are

the truly important things in life. (p. 14)

Typically, the American social relations are characterized by a "fragmentary involvement" (Harris and Moran, 1987, p. 339). Althen says that, although people in some cultures seek close, interdependent friendships (1988, p. 25) Americans relate only as the occupants of specific roles, such as worker, church member, or student (p. 26 ).

It is this researcher's contention, based on her experience as a member of the Costa Rican culture, that Costa Rican people tend to get closely involved, and as discussed earlier, they like to interact with the whole person, and not with just one aspect of the individual. While "many Americans are simply too busy to have the time that is required to get to know another person well" (Althen, 1988, p. 78), a majority of Costa Ricans take the time to get acquainted with other individuals, according to this researcher's experience.

Althen also points out that Americans are separate from each other and do not get involved with other people simply because "they do not know how to do otherwise" (1988, p. 78). As an example, Althen mentions that even neighbors in living situations may remain virtual 
In addition, Althen relates that "'superficial' is the word many longer-term foreign visitors use to describe Americans' relationships with other people" (1988, p. 78$)$. Regarding the Americans' way to interact with people, a Brazilian woman stated: "They seem cold, not really human" (Althen, 1988, p. 78). What this woman was talking about was the lack of emotional expressiveness in American people, according to her frame of reference.

Harris and Moran very clearly explain the Brazilian woman's perspective:

Americans seem to stand near the center of an emotional spectrum that extends out to embrace the effervescent Latins at one extreme and the cooly subdued southeast Asian at the other. While we appear unemotional and cold to Latins, we may appear hyperbolic and impulsive to the Asians. (1987, p.342)

Althen (1988) also comments on this issue. He emphasizes that ". . Americans generally permit more emotions to show on their faces than many Asians typically do, but less than Latins or southern Europeans" (p. 143). Pertaining to the Mexicans, Harris and Moran (1987) stress that they are "emotional" (p. 369) people. In this researcher's experience, the same description will apply for most of the Latin American societies, including Costa Rica.

In this section about relationships two specific types of social relations are going to be discussed--students' relationships with classmates and the student-professor 
VALUES

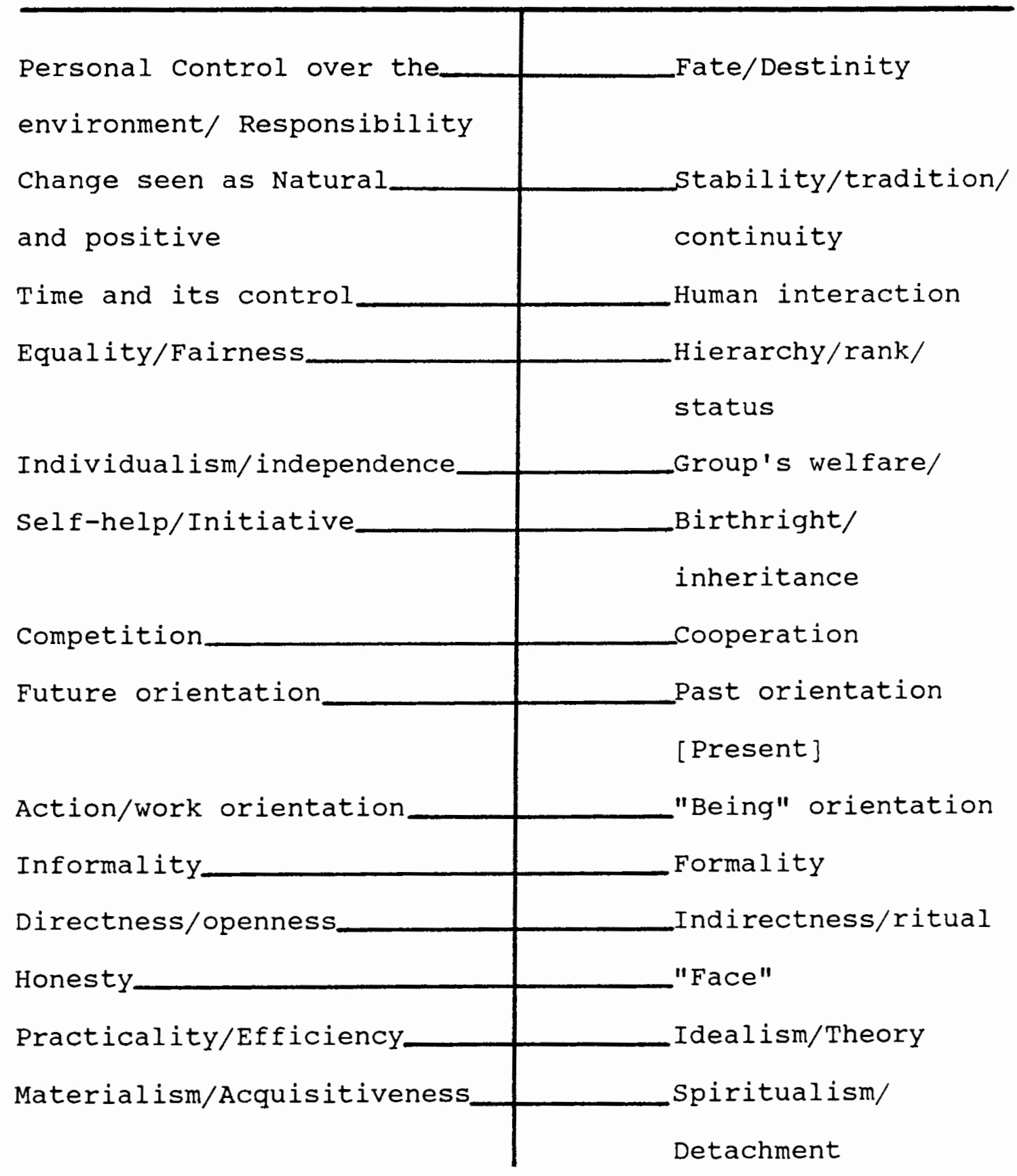

Figure 5. Kohls' Comparative Model. Source: Robert Kohls, 1987:20. 
ships with their professor than undergraduates do; at smaller schools student-teacher relationships are typically even less formal than they are at larger schools. . To say that student-teacher relationships are informal is not to say that there are no recognized status differences between the two groups. (Althen, 1988, p. 129)

There are many exceptions and circumstances that influence this type of relationship, but in general terms it seems that there is more closeness between Costa $R$ ican students and their professors. The Costa Rican way regarding the student-professor relationship, from this researcher's perception, is that, again, following the previously mentioned involvement pattern present in relationships, students and their professors do relate to each other outside of the classroom, mainly at the university level. During the lower grades and high school, the relationship student-teacher is very formal, but it changes at college level.

Costa Rican college level students--particularly, male students--usually get together with their professor after class, and informally discuss the relevant topics of the day, in addition to class issues. From what has been outlined above it seems that the student-professor relationship in the U.S. is informal in appearance but formal in context, while in Costa Rica they are formal in appearance but informal in the way they are handled.

In the Costa Rican culture the professor is responsible for his/her students' academic work. In Costa 
Rica if the student excels academically it is because the professor taught well. In contrast, in the U.S. academic norms dictate that studying is the student's responsibility and not that of the professors.

Competition--another value orientation present in the American culture--has been explained in the academic context by Althen, who describes how competition operates in the American college environment:

Many foreign students are dismayed to find that
American students do not help each other with
their studies in the way students in their own
countries do. Indeed, American students often
seem to be competing with each other rather than
cooperating. (1988, p. 127$)$
Additionally. Althen (1988) presents two possible explanations for the competing attitude of American students: American emphasis on self-reliance and the custom of grading on a "curve", which effectively puts students in the pursuit of a limited number of high grades. This manifestation of competition in the American academic environment is a reflection of what occurs in other levels of the American social context, where competition at the individual level is considered "as constructive" and "healthy" (Harris and Moran, 1987, p. 340). In the case of the Costa Rican culture, based upon the Latin American's group orientation as well as the person-oriented attitude that has been discussed earlier in this chapter, this researcher speculates that the 
predominant orientation in the Costa Rican culture is the contrasting value of "cooperation."

The last issue that is going to be discussed here relating to value orientation in the American and Latin American cultures is nonverbal communication behavior. Nonverbal communication patterns are very important, to the extent that

- . it is clear that much discomfort in intercultural situations stems from differences in nonverbal communication habits. People in cross-cultural interactions are often uncomfortable for reasons they cannot specify. Something seems wrong, but they are not sure what it is. Often what is wrong is that the other person's nonverbal behavior does not fit what one expects or is accustomed to... So, some understanding of nonverbal communication is essential for people who want to get along constructively in another culture. (Althen, 1988, pp. 140-141)

Nonverbal communication embraces a long list of aspects of communication that are not conveyed in written words or by verbal means. But, regarding this research, five main aspects are going to be touched upon--proxemics, pace of life, eye contact, phatic communication, and touching behavior.

Proxemics has to do with the way in which people use space and determine what is appropriate distance between two individuals. Gudykunst and Ting-Toomey assert that ". - the perception of space-violation and space-respect vary from one culture to the next" (1988, p. 124), they further explain that ". - the need for close personal 
space. - is reported to be high among South Americans -. and low among. . North Americans" (p. 124).

The difference between the American and Latin American approach to proxemics has been characterized by Gudykunst and Ting-Toomey:

It can be amusing to watch a conversation between an American and someone from a culture where habits concerning 'conversational distance' are different. If an American is talking to a Greek, a Latin, or an Arab, the American is likely to keep backing away because the other person is likely to keep getting 'too close.' (1988, p. 144)

The above-mentioned authors also refer to what might happen when two individuals, one from an individualistic type of culture, where more distance among people is appropriate, interact with a person from a collectivistic kind of culture where closer distance is expected. They say: "Violations of proxemic distance in individualistic cultures evoke an aggressive mode of reaction, while violations of proxemic distance in collectivistic cultures evoke a withdrawal mode of reaction" (1988, p. 26). Shuter (1976) wrote an article entitled "Proxemics and Tactility in Latin America" which contains concrete reference to Latin Americans' behavior, mainly nonverbal communication issues, that could be expected to be a problem to them when are abroad. This author mentions that "investigators have reported that Latinos--be they Costa Rican or Colombian, from Central or South America-- 
interact at a close distance and frequently touch one another during interpersonal encounters" (1976, p. 46). Why proxemics could be a problem specifically for Costa Rican students is clearly stated by the Gullahorns (1963) when they paraphrase Edward Hall as follows: "A Latin American cannot talk comfortably with another person unless the interaction partners are close to the physical proximity that evokes either sexual or hostile feelings in the North American" (p. 37).

An issue also related to the time-and-its-control value orientation, discussed earlier in this chapter, is the pace of life manifested in each culture. A brief quotation from Harris and Moran, exemplifies the difference between the American and Latin American pace of life. They point out that "visitors from a variety of African, Asian, and Latin American countries are amazed and often somewhat distressed at the rapid pace of American life and the accompanying emphasis on punctuality and efficiency" (1987, p. 341$)$.

Another aspect of nonverbal behavior that varies from culture to culture is eye contact. In Althen's words "eye contact is an aspect of nonverbal behavior that is especially complex, subtle, and important" (1988, p. 143). Althen's contention is that

- . visitors whose habit it is not to look into the eyes of a person they are talking to will be able to tell, if they are observant, that Americans are uncomfortable around them. So will those whose 
habit it is to look for longer periods or stare into the eyes of people with whom they are talking. Americans feel that something is wrong when the person they are talking with does not look at them in the way described above. (1988, p. 144)

According to this researcher's experience, Latin Americans fall in the category of people who look people in the eye for longer periods of time. Staring at people is a very common and acceptable behavior in Latin societies.

Phatic communication refers, mainly, to greeting rituals. As with the other nonverbal communication aspects, greeting rituals are different in each culture.

Considering that the American culture is fundamentally an individualistic one, the difference between American and Latin American approaches to phatic communication is concisely stated by Gudykunst and Ting-Toomey: "It takes people in collectivistic cultures longer time to engage in greeting and goodbye rituals . . " (1988, p. 131).

The issue of touch has been discussed widely in the literature. Among the authors that have presented it are Condon (1985), and Althen (1988). In addition, Gudykunst and Ting-Toomey (1988) mention, about this topic that ". - studies. . on touch behaviors in Latin American cultures and the U.S. culture reveal that people in Latin American cultures tend to engage in more frequent tactile behavior than people in the United States" (1988, p. 127). Particularly, referring to Americans' pattern of touching, Harris and Moran (1987) state that ". . they 
(Americans) are a noncontact culture (e.g., avoid embracing in public usually) and maintain certain physical, psychological distance with others. . " (p. 336). Lundberg (1960) in an observation markedly similar to that of Gudykunst and Ting-Toomey, describes the Costa Ricans attitude toward touching behavior: "Costa Ricans like other Latins seem to enjoy the handshake, the abrazo (shoulder embrace), the physical contact with friends. Handshaking is constant, expressive and seems to be reassuring to most Costa Ricans" (p. 11).

Shuter (1976) states that some authors have addressed the obvious "contact orientation" of Latin American people. In particular, he mentions Montagu's (1971) conclusions: "Tactility runs the gamet [sic] from absolute non-touchability, as among upper class Englishmen, to almost full expression in Latin Americans" (p. 47).

In general, the Shuter research, conducted in Costa Rica, Panama, and Colombia, shows that Costa Ricans tend to talk closer and to touch more than Panamanians or Colombians do when interacting on a face-to-face basis. According to this study's findings, the further one goes in South America, the more the tendency to touch seems to decrease. That is, in Central America the frequency of contact is greater than in South America, and "Costa Rica is the most tactile culture . ." (Shuter, 1976, p. 50). 
EXPECTED ADJUSTMENT PROBLEMS OF COSTA RICAN STUDENTS

Based upon Sharma's study regarding adjustment problems experienced by foreign students, Barna's article about stumbling blocks in communication among people from different cultural backgrounds, and the other authors previously mentioned in the Literature Review, certain adjustment problems could be expected among Costa Rican students living in the United States. The problems discussed by these authors in many cases may be the same as those faced by Costa Rican students.

To speculate on the adjustment problems that costa Rican students might encounter, the previously mentioned information about adjustment problems of foreign students will be drawn upon. Also, the information obtained from two other sources will be used. One of these sources is Raul Martinez, Director of the International students Services (I.S.S.), at Portland State University (P.S.U.). The other is a group of Costa Ricans who are living in Oregon and who were the subjects of the preliminary survey that was conducted for the purpose of this study (refer to Appendix A). The last two sources are going to be discussed in the methodology chapter.

The expected problems of adjustment that costa Ricans might encounter are listed in the "Inventory of Expected Problems of Costa Rican College Students" (see Appendix B). As suggested here and discussed later in Chapter III, this 
inventory is a collection of the adjustment problems, which deal with value systems enumerated in the previously mentioned sources--Literature Review, an interview and a preliminary survey.

The following is a list of the most frequently mentioned adjustment problems that have been identified in the literature. This list is a selection of all the problems considered relevant according to this thesis topic.

\section{$\frac{\text { List of Expected Adjustment Problems }}{\text { of Costa Rican Students }}$}

\section{Language}

Homesi ckness

Isolation Social interaction with hosts

Meaningful relationships

Nonverbal communication (time, proxemics, touching, eye contact)

Loneliness

Discrimination

Conflict of values: (These are the American values that may become a source of conflict to costa Ricans)

Control over environment

Change is natural and positive

Time and its control

Equality

Individualism

Initiative

Competition

Future orientation

Action orientation

Informality

Directness

Practicality

Materialism

A review of the literature shows that there is no easily obtainable study about the adjustment problems unique to Costa Rican college students. The few specific 
references that have been found in the literature, have been stated in the previous sections of this chapter. 
CHAPTER I I I

METHODOLOGY

GENERAL APPROACH

This study constitutes an exploratory approach that combines a descriptive method as a means of data collection with grounded theory as a qualitative method of data analysis. The purpose of this study is to generate information and develop hypotheses.

The research undertaken here will produce information about Costa Rican students' behavior, their specific customs, and primarily their adjustment problems in terms of their value system. These data are not available now in the intercultural communication literature. Based upon the descriptive approach, this thesis attempts to shed light on the intercultural issues of costa Ricans studying in the U.S. In this sense, this is a study that could generate hypotheses for future research.

Among the functions of the descriptive method are: to establish needs or problems; identify effects or outcomes, discover relationships; and relate attitudes to behavior (Tucker, Weaver, and Berryman-Fink, 1981). Considering the nature of this study, the above-mentioned applications of descriptive research suit the study's 
objectives. In addition, the descriptive methodology has been chosen because it is useful to explain descriptively rather than in numerical terms, the situation of the population considered in this study.

In this vein, Tucker et al. point out that "descriptive researchers collect information about events, beliefs, attitudes, values, intentions, preferences or behaviors. They collect this information through the use of surveys, interviews or observations" (p. 121). This thesis, as a descriptive research project, uses the interview approach as the data-gathering tool to answer the research question. In regards to the interview, Smith

(1975) mentions in his book, Strategies of Social Research, that interviews "provide one of the few techniques available for the study of attitudes, values, beliefs, and motives" (p. 196).

In addition, referring to the interview, Tucker et al. (1981) explain: "The interview is a data-collection device in which an interviewer orally administers a set of prepared questions to an interviewee.. . The interview is a beneficial tool when you want complete or detailed answers to questions. . " (1981, p. 121). According to Maccoby and Maccoby, quoted by Smith (1975), "an interview is a peculiar verbal interactional exchange ' in which one person, the interviewer, attempts to elicit information or 
expressions of opinions or belief from another person or persons' " (p. 170$)$.

For the purpose of this research, a specific type of interview has been used, that is, the "in-depth" or "intensive" interview. Taylor and Bodgan (1984) say: "By in-depth qualitative interviewing we mean . . face-to-face encounters between the researcher and informants directed toward understanding informants' perspectives on their lives, experiences, or situations as expressed in their own words" (p. 77).

The main characteristic of this research tool is emphasized by Taylor and Bodgan when they write: "The hallmark of in-depth qualitative interviewing is learning about what is important in the minds of the informants: their meanings, perspectives, and definitions; how they view, categorize, and experience the world" (1984, p. 88). Lofland and Lofland (1984) describe the "in-depth" (intensive) interview's fundamental trait as follows: ". - the intensive interview seeks to discover the informant's experience of a particular topic or situation . • , [and] to find out what kinds of things exist in the first place" (p. 12$)$.

There are several reasons for using the intensive interview as a research tool. According to Lane, quoted by Graber (1984), one is that such interviews are "discursive", that is, they permit the participant to think 
his or her answer through thoroughly. A second reason is that "when combined with tape recordings, interviews provide an accurate textual account of everything said" (p. 17). And, lastly, the intensive interviews are "biographical." This means that the information obtained from the interviewees is about their own experiences, which means that the information is drawn from the very sources that have it.

There are other main advantages in using this tool. For instance, Taylor and Bodgan mention the fact that it allows a researcher "to study a relatively large number of people in a relative short period of time" (1984, p. 79) compared to other kinds of techniques such as participant observation. Lofland and Lofland (1984) suggest that intensive interviewing "is the best if not the only way" to collect information when researching experiences that are specific to every person. Another advantage is that, in spite of the fact that each interview constitutes an individual experience, this device allows one to identify the common threads present in each different situation (Taylor and Bodgan, 1984). Finally, there is the fact that a dialogue is more culturally appropriate than a questionnaire, when the researcher asks people (in this case, Costa Rican students), in a face-to-face interaction style, about their own intercultural experiences. 
In order to present all respondents with the same stimuli so that they are responding to the same research instrument, the researcher or interviewer has to develop a schedule of questions. The interview schedule has been defined by the Loflands as ". . a list of things to be sure to ask about when talking to the person being interviewed" (1984, p. 59).

One of the main traits of the interview schedule is that it is open-ended. According to Smith "an open-ended question is a question that leaves the respondent free to respond in a relatively unrestricted manner" (1975, p. 172). Smith, (1975) quoting Cannell and Kahn, suggests that the foundation of a good interview schedule is the proposition of questions that provide "maximum opportunity for complete and accurate communication of ideas between the researcher (or interviewer) and the respondent" (p. 171). The specific interview schedule that serves the purposes of this study will be discussed in detail later in this chapter.

Grounded theory constitutes the second methodological approach used in this thesis. Taylor and Bodgan describe it as ". . a method for discovering theories, concepts, hypothesis, and propositions directly from data . . " (1984, p. 126). This same concept is defined by Glaser and Strauss as they write: "In discovering theory, one generates conceptual categories or their properties from 
evidence; then the evidence from which the category emerged is used to illustrate the concept", (1967, p.23).

One of the main characteristics of this method is that, "in generating theory, researchers do not seek to prove their theories, but merely to demonstrate plausible support for them" (Taylor et al., 1984, p. 126).

Generalization of the findings is not the main purpose of this kind of research. According to Taylor and Bodgan (1984) as well as Glaser and Strauss (1967) this approach is good for use on social units of any size. Referring to this topic, Glaser and Strauss remark: "the number of cases is. . not so crucial" (p. 30), the information generated from each case is what counts. In sum, the foundation of grounded theory lies on the fact that the "researchers develop concepts, insights, and understanding from patterns in the data, rather than collecting data to assess preconceived models, hypotheses, or theories" (Taylor and Bodgan, 1984, p. 5).

According to Taylor and Bodgan, grounded theory is subdivided into three main phases:

The first is an ongoing discovery phase: identifying themes and developing concepts and propositions. The second phase, which typically occurs after the data have been collected, entails coding the data and refining one's understanding of the subject matter. In the final phase, the researcher attempts to discount his or her findings... "that is, to understand the data in the context in which they were collected. (1984, p. 13ø) 
Regarding this specific study, the three phases are described as follows. Phase one of the research involves the generation of themes from three major sources:

Literature Review, ; especially Sharma's "Foreign Students Problems Inventory"; an interview with Raul Martinez, Director of the International student Services at Portland State University; and a preliminary survey (see Appendix A). These three sources were consulted in the above specified order. For details regarding the first source, refer, to Chapter II. A brief explanation and results about the second and third sources will be included later in this chapter.

Phase Two includes three steps. In one, based upon the data collected through Phase One, the researcher looks for new themes arising from Mr. Martinez's interview and the preliminary survey results, and selects themes from the reviewed literature for follow-up in the interviews. The second step is to develop an inventory of expected adjustment problems of Costa Rican students (see Appendix B). Then, in the third step, an interview schedule is generated as a data collection tool (refer to Appendix C), based on the inventory developed in the second step of Phase Two. More details about the inventory and the interview schedule are included later in this chapter. Last, in Phase Three the information gathered through the interviews is analyzed in order to create additional 
new themes, and data is analyzed in terms of the concepts, both general and specific, mentioned in the Literature Review and the Inventory of problems of Costa Rican students. The entire Phase Three is presented as Chapter V--Data Analysis.

Before discussing the other sections of this Chapter, Phase Two of the Methodology will be expanded upon. As mentioned above, the first part of the first step of this phase is contained in chapter II. So, in the following sections the second part of this same first step (the interview with Mr. Martinez and the preliminary survey) will be stated and the results will be reported. Then, the development of the inventory and the development of the interview schedule, as steps two and three of Phase Two, will be explained.

\section{PERSONAL INTERVIEW AND PRELIMINARY SURVEY}

Mr. Martinez was interviewed (November, 1988) in order to gather information about the adjustment problems faced by Portland State University foreign students, in general, and particularly by Latin American students, including the few Costa Ricans that have attended this University. Mr. Martinez, who is from uruguay, based his responses upon his personal experience as a Latin American student in the U.S., and his knowledge of Latin American students, acquired through his 13 years as director of the International Student Services at Portland State University. 
According to Mr. Martinez, the most common and intense problems that Latin American students encounter in adjusting to the American culture are: use of time; family relations; and uneasy interpersonal relationships, especially with classmates, professors and staff. In addition, he emphasized the issue of friendship as one of the major problems for almost all foreign students.

From the preliminary survey, this researcher obtained some specific data referring to what Costa Ricans considered to be problems in their adjustment to the U.S. The preliminary survey (see Appendix A) was administered to ten Costa Rican students, with a total response of seven filled-out questionnaires. The returned questionnaires provided some information useful in organizing the inventory of expected adjustment problems of Costa Rican students and later the interview schedule. The use of this information in generating "Themes" is explained later in this Chapter. Information from the preliminary survey that was useful in developing the themes was obtained mainly from the responses to questions $19,22,23,25,26,27,28$, $29,30,31,37,38,39,40,41,43,44,45,51$ and 54. In general terms, the adjustment problems of Costa Rican students, as perceived and reported by the students themselves, are the U.S. emphasis on competition, the materialism present in the American society, individualism as a common attitude of American people, family 
relationships, friendship, language, interpersonal relations (mainly with American classmates), and phatic communication.

\section{DEVELOPMENT OF INVENTORY}

An inventory (refer to Appendix B) was developed to summarize the expected adjustment problems that costa Rican college students face in the U.S. This inventory is the sum of the problems recorded in the Literature Review sections about general adjustment problems, adjustment problems pertaining to foreign students, and the issues listed in the section regarding expected specific difficulties encountered by costa Rican students. In addition to the cited sources, the inventory is based upon information obtained from Mr. Martinez's interview and data collected through the preliminary survey of Costa Rican students, as previously mentioned.

The inventory contains five themes: academic; personal; social; communication; and value differences. The first three themes are mainly based on the inventory developed by Sharma (1971), but also include issues discussed by Brislin (1984), Eurnham and Bochner (1982). The results of Sharma's study (see Chapter II) more than the actual inventory of problems devised by her are what constitute the foundation of the inventory developed for this study's purposes. The original inventory is modified for the purpose of this thesis by trying focus on 
issues more related to value differences. In some cases, all the problems listed by Sharma were left out, keeping only the main category and replacing the listed problems with new ones pertaining to value differences. For instance, the first theme of the inventory proposed by this thesis' researcher refers to the first category of problems mentioned by Sharma (1971) in her study, but not to the subthemes contained in it.

Another modification is to Sharma's theme of Academic Problems. She lists subthemes such as taking notes and giving oral reports, while the contention of this thesis' author is that in the academic environment foreign students not only face such "logistic" problems but also intercultural difficulties such as communicating with faculty. This thesis will focus on problems foreign students have when interacting with faculty and classmates, and their general behavior as students. To clarify this distinction, the name of this category will be slightly changed from "Academic Problems" to "Academic Context Problems".

In the case of the second theme, the name of the category--Personal Problems--is borrowed from Sharma and the issue of homesickness has been kept, while issues such as food, housing, and finances were left out, for the previously mentioned reasons. In addition, loneliness is a 
concept mentioned by Furnham (1987) that has been added to this theme.

Pertaining to social problems, the themes contained in this inventory are mainly the ones mentioned by Sharma. These themes has been slightly paraphrased and their final wording is as follows: social interaction with Americans; making friends; establishing meaningful relationships; and being isolated from the mainstream.

In addition, Sharma's inventory is expanded by adding the last two themes. The fourth theme is based mainly upon Barna's (1985) ideas about stumbling blocks in intercultural communication. The concepts included in this theme are language, phatic communication, nonverbal communication, and high anxiety. This researcher borrowed the following from Barna: language; nonverbal communication; and high anxiety.

In the nonverbal communication theme there are contained issues mentioned by Barna--time, proxemics--but there are also issues discussed by other authors (Condon and Yousef, 1987, and DeVito, 1985), such as touching and eye contact. Phatic communication is a concept borrowed from Condon and Yousef (1987). The fifth theme, pertaining to value differences, was developed from Althen (1988); Condon (1985); Kluckhohn and Strodtbeck (1961); Kohls (1987); and Whyte and Holmberg (1956). This theme focuses 
on the following issues: competition; materialism; individualism; family relations; and time orientation. Regarding the terms used in the inventory, there are some that have not been clearly defined either in the general literature nor in Sharma's inventory. They are concepts that might be ambiguous in some way. These terms are loneliness, homesickness and meaningful relationships. For the purpose of this research they are going to be defined as follows.

In this study, loneliness is defined as psychological isolation. It is a condition that one could experience at home as well as abroad. Homesickness, on the other hand, is defined here as a strong desire for home and family when in another country or away from home. Thus concerning this study, they are not used as interchangeable terms. One might feel lonely but not necessarily homesick, or vice versa, or both.

Referring to "meaningful relationships," it is a concept that means a warm and close relationship. It could be a relatonship between neighbors, between professors and students, between staff and students, or between classmates. It does not necessarily mean relationships with significant others.

Also, it is this researcher's contention that there are two more terms that need to be clarified. They are: time and time orientation. On the one hand, time, listed 
in nonverbal issues in the communication problems theme (Theme IV), refers to the use of time and the pace of life in a given society. This has to do, for example, with the norms in a specific culture regarding punctuality, deadines and the fast or slow pattern of activity in a particular society, on an everyday basis (Barna, 1985; Condon and Yousef, 1987, and Levine, 1985).

on the other hand, time orientation refers to the general attitude people held toward time in a given society. According to Kluckhohn and strodtbeck a culture could be past-oriented, present-oriented or future-oriented (for more details on this matter refer to pages 3 and 4 of this thesis).

\section{DEVELOPMENT OF INTERVIEW SCHEDULE}

As it has been stated, the intensive (in-depth) interview has been used as the major tool in this research. The interviewer asked questions using an Interview Schedule (see Appendix C) which was developed by this author based on the proposed inventory format mentioned earlier. The interview schedule is used to obtain information to see how the inventory reflects the real intercultural adjustment problems of costa Rican students. The Interview Schedule is short and composed of only open-ended questions in order to obtain detailed information from each participant.

An introductory section of the Interview Schedule is used to collect demographic data necessary for knowing more 
about each subject and the population as a whole. This information could lead to interesting insights in the analysis of the data.

Question content and focus.

Question \#l relates to Theme IV (Communication Problems) of the Inventory. It is used to find out if language could be a communication problem for costa Rican students as it has been suggested by Barna, in the Literature Review. The second question acts as an introduction to the topic, allowing the interviewee to talk freely about what he or she considers to be a problem in adjusting to American culture.

Question \#3 inquires about the academic context problems listed in Theme I of the Inventory (see Appendix B). The next question focuses on personal problems considered in the Inventory in Theme II.

The aim of question \#5 is to explore the social problems mentioned in Theme III of the Inventory, regarding social interaction of Costa Ricans with Americans. The answers to this question will provide information about whether Costa Rican students have difficulties making friends with host students. Reports of social interactions of Costa Ricans help to determine if they relate more often with Americans, countrymen or other foreigners.

The purpose of questions \#6, \#7 and \#8 is to research aspects included in Theme IV. This theme deals with communication problems such as high anxiety, language and 
nonverbal communication including phatic communication, use of time, proxemics and the like. Question \#9 asks specifically for value differences. This is a general question that allows the interviewees to talk about their own experience in terms of value differences they have noticed between their own culture and the American culture. As mentioned in Theme $V$ of the Inventory (see Appendix B), it was assumed they would discuss value differences including individualism, friendship, and family relations. Questions \#10, \#11 and \#12 help to generate new information referring to this thesis' topic. First of all, question \#ID explores whether costa Rican students are adjusting to the American culture, according to the definition of adjustment stated in the Literature Review Chapter. Second, question \#11 explores whether there are similar responses on major problems in adjusting for costa Ricans. And finally, question \#12 allows the interviewees to add any comments or observations concerning their experience as foreign students living and adjusting to their host culture.

POPULATION AND SELECTION OF THE SUBJECTS

The population for this study included Costa Rican students attending college in the state of oregon, enrolled in a program of two years minimum. This last criterion is very important because it means that the 
subjects are "long-term" sojourners as opposed to immigrants or "short- term" sojourners.

The time they spent in this country has been considered as a main characteristic of the population, to the extent that it is going to have an impact on sojourners' perspectives about their experience in general, and also on the kind of interaction they will have with host people. There are four categories of sojourners according to their length of stay--tourist, short-term sojourners, long-term sojourners, and immigrants. According to Brislin (1984) a tourist is a person whose stay in another country is no longer than three months. DuBois (1956) considers "short-residence group" ( $p$. 7Ø) a group of people whose stay in a foreign nation is less than six months. A long-term sojourner is an individual who remains in another country for one, two or more years (Brislin, 1984). Einally, because a definition of "immigrant" is not found in the literature, for this thesis's purposes, an immigrant is defined as an individual seeking to $l$ ive in another country if not permanently, at least for an extended period.

Brislin, in Cross-cultural Encounters (1984), discusses the differences in attitude held by people visiting another culture in relationship to their iength of stay and their motivation. That is, people who visit another culture as "tourist" have a different attitude 
toward and perception of the host culture than would people who are studying or working in that culture for a "long-term". In this vein, "immigrants", without doubt, will have a different experience than those in the "short-term" or "tourist" categories mentioned above.

For this study's purpose, students are a part of that group of people who have a particular motive for being in another culture, and whose stay is often considered extended. Therefore, their experience and their interaction with host people are marked by particular traits, some of which have been cited in chapter II.

In sum, the criteria of selection of this study's population are: country of birth (Costa Rica), status in the visiting country (students pursuing a degree in the U.S.), planned stay period in the host country (long-term), and place of residence in that country (oregon).

To obtain participants for this study, I contacted the International student or International Services offices in all universities and colleges in the oregon area to find Costa Ricans in attendance. Personnel within these offices gave information about the study to costa Rican students and told them who to contact. Once personal contact was established with some of the students, they introduced me to the other countrymen in that particular educational center. This technique is called "snowballing" (Taylor and 
Bogdan, 1984), and it is described as "getting to know some informants and having them introduce you to others" (pp. 83-84).

There are some Costa Ricans living in the state of Oregon who are not included in this study because they do not meet the selection criteria outlined above. Many of them are immigrants, and a few are students planning to remain as residents in the U.S. It has been explained above that this condition gives them a very different perspective regarding the adjustment process. Another group of people from Costa Rica not included in this population are the students in exchange programs or any other types of training or study programs that last just a few months, for the aforementioned reasons. Also, four other students have been excluded due to the fact that they were a part of the group that filled out the questionnaire used in the preliminary survey.

After establishing contact with all the students, the researcher explained to them the purpose of this study and asked their consent to participate. The researcher also assured participants that all information generated in the interviews would be confidential.

Thirteen Costa Rican students were located in six higher-educational institutions in Oregon. The 13 students were screened based on the selection criteria. However, the final population is composed of 11 respondents. Two of 
the interviews are deleted from the final outcome. One of the withdrawn interviews consisted of two students who are a married couple, who asked that they be interviewed together, mainly for time reasons. This researcher agreed to do so and considered it as one, primarily because one of the partners dominated the conversation. Also, when the second partner intervened, he or she expressed similar ideas, most of the time supporting his or her partner's statements.

In the second case, the interview was withdrawn because this researcher considered it to be incomplete. This interviewer failed several times to obtain more information from the interviewee whose answers were unusually brief. While the interviews $r$ an an average of two hours, this particular interview lasted only thirty minutes .

The subjects will be represented in the Results Chapter by number. The principal reason for doing this is to mantain the anonymity assured to the subjects. The number has been assigned according to the order in which they were interviewed. Therefore, sl means the first subject interviewed and sll the last.

The selected population is considered to be a typical group of Costa Ricans, with the exception of subject 11 who has some characteristics that may influence in some way his or her perception about this experience of being a student 
in a foreign country. Subject 11 is married to an American, has 1 ived in this country before, and has had experience working with Americans in Costa Rica.

Overall, this population is composed of three females and eight males. The subjects' ages range from 22 to 38 years, the average being 29 years. Regarding academic status, the participants include three undergraduate and eight graduate students. Seven of the ll students are enrolled in science programs while four are involved in social science areas. Concerning the stay period, the costa Rican students plan to remain in the U.S. an average of three and a half years. Most of them have been here about two and a half years, and will remain approximately one more year.

\section{INTERVIEW PROCEDURE}

This researcher conducted all interviews. As explained earlier in this chapter, the technigue used for the purposes of this study was the intensive interview. The interviewer used a combination of note-taking and tape recording to gather the most complete information. The procedure used the tapes as a way to complete and clarify the notes, by listening to the tapes and writing down exact statements. In this way, the researcher was able to collect more accurate data.

Interviews ran an average of two hours. The shortest lasted one hour while the longest two and a half hours. 
The interviews took place in a variety of places including interviewee's homes, offices, and other quiet public places. The participants were given the choice of the location they found most comfortable and convenient. This encouraged maximum disclosure.

Even though the interviewees are a bilingual population, the interviews were conducted in Spanish. Regarding this matter, it is this researcher's contention that the subjects felt more comfortable, and the information gathered was more accurate because the respondents were able to express their feelings and experiences more precisely in their native language.

Generally speaking, the interviewees were very open and willing to share their experiences with the interviewer, with the exception of one who was defensive and rationalized all the answers. The rest of the interviewees were very spontaneous when answering the questions. None of the interviewees seemed to be bothered by the tape-recorder, which allowed the researcher to sustain a relaxed dialogue with most of the interviewees.

The interview schedule (see Appendix C) was used as a guide, but in an open way. It was used more in a conversational style than in a fixed manner by following the order of the questions. The exceptions were the demographic data collected at the beginning of each interview and the first and the last questions on the 
Interview schedule, which were asked in that specific order. The researcher allowed the interviewees to talk about their experiences relevant to the study and made sure that all the aspects of the Interview Schedule were covered. In sum, the order of the questions on the Interview Schedule did not affect the outcome; more relevant were the interviewees' experiences, as they told them.

\section{DATA ANALYSIS PROCEDURES}

This study explores the adjustment problems faced by Costa Rican students while they attend college in the U.S. The main focus of this thesis is the adjustment problems that arise from the differences in value systems that exist between the costa Rican and American cultures.

The study is concerned with the subjective experience of the interviewees as they report it. The researcher will analyze responses to the survey and interview to determine their relevance to issues defined in the literature and their support of new themes which emerged from the preliminary survey. Specifically, the researcher will compare the results of the interviews with the Inventory of Expected Problems to see if the adjustment problems manifested by the students themselves are the same as the expected adjustment problems included in the Inventory.

In addition, the demographic data pertaining to the interviewees will be analyzed to explore the relationship 
between adjustment problems reported by costa Rican students and demographic variables such as age, sex, area of study, academic status and stay period. 
CHAPTER IV

\section{RESULTS}

The following chapter contains objective reporting of results found through the interviews. Quotations from the interviews are used to illustrate and support the findings. The results will be presented according to the themes included in the Inventory. They are: Theme I (Academic Context Problems); Theme II (Personal Problems); Theme III (Social Problems); Theme IV (Communication Problems) and Theme V (Value Differences).

\section{THEME I}

Results of the interviews revealed that costa Rican students seem to face difficulties in some of the aspects included in Theme I (Academic Context Problems). This first theme includes relationship with students, relationship with faculty, and the student's role in an American classroom. Seventy-three percent of the students indicated they have problems with their relationship with classmates, mainly American classmates. This total of $73 \%$ is composed of eight interviewees. Three of them indicated not having any relationship at all with American students; two of the eight qualified their relations as "cold", while one labeled them as "superficial". "Here it is different. 
There is no such atmosphere that allows you to relate with your classmates. - " (SI). "I had to learn this lesson: They do not interact with me. . I do not interact with them. - as simple as that" (S2). Also, s8 has disclosed the same idea as 52 . In addition, 53 stated: "I have noticed this cold attitude only in Americans. Foreign students are not like that, Arabs, Chinese or Italians are more talkative and friendly . . . "

Regarding relationships with the faculty, $45 \%$ of the Costa Rican students indicated they had encountered problems in this area. Interviewees expected professors in general to be more understanding with international students and they found that characteristic in only a few professors. "Only professors who have had intercultural experiences are more sensitive to my problems . . " (Sl). "I was expecting more help and understanding from my professors, but the only ones that have proved to be more sensitive are those who have traveled and/or have had the experience of being foreign students themselves" (S5). A different kind of problem was reported by 58 , who commented: "My problems with professors are, fundamentally, language problems. I wish I could communicate better with them."

Also, $27 \%$ of the interviewees said that the relationship between students and faculty is different from the one that they are accustomed to at home. Here, it is a 
professional relationship exclusively. The fact that the professor-student role is very well kept and that professors do not go beyond that seems to bother some Costa Rican students.

According to $55 \%$ of the interviewees, there has been no problem in their relationship with faculty, and some, on the contrary, like the system. They like the fact that students do not get involved with professors in a friendly relationship and 1 ike even more that professors have specific office hours for the students to come and discuss class issues with them or just to ask questions.

The last issue in this theme is the student's role, which does not seem to be a problem for the interviewees. While $64 \%$ of the Costa Rican students did not mention anything about the role students play, $36 \%$ noticed differences between expectations of students here in the U.S. and in Costa Rica. Among the differences listed by the interviewees are that "the student is the only one responsible for his learning and his grades" (S3), and "the student has to work as much as professors do, in the sense they have to write papers, do research and participate in class discussions. . ." (Sll), and finally, "what the student has to say is important" (S4). Regarding this last comment, in addition to $\mathrm{S4}$, one student liked hearing views of other students (S6), while another (Sl0) did not. As he or she said, "I go to class to learn from the professor and 
I do not care about what my classmates think.... " In addition, the interviewees talked about individualism and competition issues that will be discussed in depth in Theme V (Value Differences).

THEME I I

Results from the interviewees revealed that costa Rican students were more lonely than homesick. Fifty-five percent of the interviewees reported experiencing loneliness, while only $45 \%$ disclosed being homesick quite often. Four of the eleven interviewees experienced both homesickness and loneliness. "My first year here was very hard. Even though I was satisfied with my academic work, I was very lonely" $(\operatorname{SI} \emptyset)$. Another subject remarked "I miss my family, sometimes I think about how lonely I am here and how far away I am from my country" (S8).

\section{THEME I I I}

Eighty-two percent of the population indicated having problems interacting socially with Americans. This can be seen in the following quotes:

Human relations are very cold here (U.S.A.).

Furthermore, there is an additional problem, you never know what is appropriate; never know what to wear; never say what you should say; never know what is correct, and finally, never know what you should know. (SI)

"I find Americans difficult to interact with because they are full of prejudice and stereotypes . . . They are always in a hurry and the concept of a refreshing pause 
during the day does not exist here" (S2). "It is very difficult to interact with Americans unless they have traveled or have had any kind of international experience - . "(S4). Sl, s2, S7 and $51 \emptyset$ shared these sentiments. "In general, Americans are superficial, and it is difficult to establish a deep conversation with them - . communication is easier with other internationals" (S8). The remaining 18 o did not mention any problems interacting socially with Americans.

Only $9 \%$ of the Costa Rican students had not encountered any problems making friends with Americans, whether the Americans were students or not. But, $91 \%$ found making friends one of the biggest problems in adjusting to American culture. "Here, there is no such a person that one can call friend. I cannot say that I have friends as the ones I used to have in my country" (s2). "All my friends are foreigners, I do not have any American friend" (S5). Other comments were, for example, "I can count my American friends with the fingers of my hand and still have Eingers left..." (S7), and

I have been here almost three years and I have just a few friends. . . and one thing that I still do not understand is that there is no such relationship unless there is a specific interest. I have noticed several times that who gets close to me is because he or she has a particular interest, I either have or do something that is of this person's interest. (s9) 
Another remark was: "One thing that is very confusing is that American people seem to be very friendly one day and if you see them the next day they do not even bother greeting you" (Slø). A similar observation was made also by $\mathrm{S} 5$.

More than half of the Costa Rican students interviewed (55\%) said they are experiencing problems with meaningful relationships. "American people, in general, are very superficial, the ordinary individual does not relate to foreigners. Those that one may call deviants in their own culture are the ones that are more sensitive..." (Slø). "My relations with Americans are cold, mainly because they defined them that way. I have tried to have warmer relations with Americans but it seems that there are strong barriers . ." (S2). Regarding this issue, another interviewee commented that "it is a strange feeling, because one cannot say that people here are rude, they are amiable, nobody mistreats you; however, you never feel comfortable around people. Even your neighbors or coworkers mantain certain distance in their relations with you" (S3). "Again, only from those Americans that have traveled or have had any $k$ ind of intercultural experience you can feel human warmness . . " (Sl).

Isolation is a problem experienced and discussed by $55 \%$ of the population. The remaining $45 \%$ did not discuss this as an issue. "Americans' strong respect for the 
individual and privacy makes you feel isolated . . " (s3). "I used to live in a dorm, nobody said hello to me in the hall or at the main entrance. At the cafeteria everybody sat, ate and left . - I felt very isolated, nobody would talk to me," s7 pointed out. Another interviewee emphasized that "it really is awful to feel that you are not a part of the group, that you are not in your own environment. . " (S9).

\section{THEME IV}

The fourth theme has been broken down into four main subthemes: language; phatic talk; nonverbal communication; and high anxiety. Answers to question \#l and questions from \#6 through \#8 (see Appendix C) provided the following results. Four of the eleven interviewees have a very good command of the English language and did not need to study English. In other words, as soon as they arrived here they enrolled in their academic programs. Another four of those eleven did not know anything about the host language and had to learn it here. The remaining three knew some English but not enough to attend college, so they also took some English courses to improve their command of the language.

Sixty-four percent of the respondents indicated that language really constitutes an adjustment problem for them. The above 64 includes the four who learned the language here, two of the four who knew it before they got here, and 
only one of the three that knew some and learned more here. A typical response was "It is a big limitation not to be able to express yourself in another language as you are used to in your native language" (S2). Another subject expressed, "It really was difficult when I did not know how to speak English. . " (S3). In addition, s5 commented: "It was very difficult when I was learning the language - . At that time I could not adjust at all to my new environment."

Phatic communication seems to be a problem to 55\% of the interviewees while $45 \%$ do not seem to be disturbed by the differences in customs that exist between American and Costa Rican cultures regarding greeting rituals and small talk. Some of the Costa Rican students indicated feeling uncomfortable during phatic interactions with host students. They reported: "We (Costa Ricans) used to say hello to everybody at the office and have a little talk. Here, when I go to my offices and I greet people, I expected them to talk a litle bit, but, at best they would just say 'Hi'" (S3). "Now I am used to that, but it took me a long time to learn not to stop to talk to people when I run into them. Before, I stopped to talk to them and not too later realized that they just said 'Hi', continued running and left me with the words in my mouth" (S4. Nonverbal communication was divided into four subthemes: use of time, proxemics, eye contact, and 
touching. The results revealed that $1 \emptyset \emptyset \%$ of the interviewees did not have any problem with promptness. The Costa Rican students interviewed have problems confronting the American idea that "time is money" than dealing with the concept of being on time. "It seems that here every minute is worth a thousand dollars, let's say, and if you waste a minute, it is considered a crime" (S7). "They set times even to have fun. They say, for instance, the party is from 6 p.m. to 10 p.m., like if they stay longer they are wasting time and therefore money" (S8). Findings showed that $64 \%$ of the interviewees did not have any problem adjusting to the "always-in-a-hurry" American lifestyle. However, the remaining $36 \%$ reported noticing the difference and had to make changes in their lifestyles to adjust. "In general terms, I think now I am adjusted to the pace of 1 ife in this country, and I am able to make it to all my obligations. However, I would never be able to live my life minute by minute and I would not be that strict with my time. Time is something more flexible to me.. " (S5).

While $27 \%$ of the interviewees mentioned encountering problems with the use of space, $73 \%$ disclosed not having problems in this area. One of the few who mentioned the use of space as a problem said, "I have noticed that they (Americans) feel pretty uncomfortable when you get close to them. They even tend to move back" (S4). A typical 
response of a student who did not consider this to be a problem was: "I know that they (Americans) need more space than we (Costa Ricans) do. So, I try to keep the distance" (S7).

Most of the students did not mention problems with eye contact. Nine of the eleven interviewees ( $82 \%$ ) did not report having problems with this issue, while two experienced problems in this sense. Among the students who considered this not to be a problem, one stated, "We (Costa Ricans and Americans) are similar regarding when and for how long to look one another in the eyes" (S3). Whereas, another student reported, "Here, eye contact is more frequent than it is for us and also more important... . They are suspicious of people who do not look them straight in the eyes" (SII).

The final aspect considered in the nonverbal communication subtheme is touch. Findings revealed that touching is a minor problem to $64 \%$ of the Costa Rican students. One student specifically claimed encountering problems with hand-shaking. "It took me a long time to realize that people here do not shake hands as often as we do. I used to offer my hand to my classmates and friends until I noticed that it was a mistake..." (S5). S9 disclosed that he or she has a tendency to touch people and immediately noticed a negative reaction in American people. "Americans exibit a very strange reaction when 
somebody touches them . . . It seems like it is a major violation" (ST). "I will never forget my friend's reaction when I greeted her with a kiss on her cheek. It was almost as if I have attacked her," s6 remembered.

The remaining $36 \%$ indicated an awareness of the fact that the American culture is not a "touching" one. It is clear to them that Americans do not touch one another as often as Latin American people. Knowing this, they avoid touching people. However, they miss the physical contact to which they are accustomed. "I miss people's effusiveness, expressivity and warmness. Sometimes I wish somebody would touch me and remind me that I am surrounded by human beings," remarked 58 .

While $27 \%$ indicated they had not experienced problems of high anxiety, a majority, consisting of $73 \%$ of the costa Rican students interviewed mentioned suffering stress and depression at least once during their stay in the U.S. Following is a statement that demonstrates this finding:

When I went back to Costa Rica for a vacation, I realized how insecure and anxious I felt here. Back there I experienced a general relaxing feeling . . . I did not have all the additional preoccupations I used to have here, like wondering all the time if I have behaved appropriately, if I have said the right thing, or if I have made any other kind of mistake. (SI)

THEME V

In this category are included specific American values that might be difficult to deal with for Costa Rican 
students. The results revealed that $82 \%$ of the students found strong differences in the value concerning family relations. Following are examples of responses that support the results: "I come from a very large and close family and I really miss my family's support . . the smallest problem here turns out to be two or three times bigger because I do not have them here with me" (S7). Another subject commented: "Even though my host family is very nice with me, I really don't feel completely incorporated. The problem I think is that even they are not incorporated" (S4).

Seventy-three percent of the interviewees thought that competition is a value they had to make an effort to get used to. Twenty-seven percent of the population interviewed seemed not to be bothered by it. The following statements are examples of the way of thinking of those who saw this as a problem: "The American society is extremely competitive and one can notice it at school, at work, in sports, between sexes.. - It seems that they transform any activity into a contest in order to enjoy it" (S8). "I come from a system in which you do not compete against anybody, for example, my grade is my grade; but here there is a lot of competition due to the evaluation system in which someone else's grades could affect my grades" (S5). In the same vein, $S 6$ emphasized that the competitive attitude of Americans places a lot of pressure on the 
foreign students because they "not only compete against themselves, but against other foreigners as well and, what is harder, against Americans. This means that you have to work very hard in order to keep up with Americans."

S2 went further saying: "The American competitive attitude is very shocking because in my own culture the spirit of cooperation prevails. The group is above the individual."

Fifty-five percent of the interviewees felt they had to adjust to materialism as well as to individualism as strong values present in the American culture. Typical statements regarding the former issue were: "In this society everything is translated in terms of material things. You are who you are in terms of what you own. In my country, we also appreciate material things, but they are not so important" (S2). And, "It is easier here for people to give you material things than affection . . This is a very rich country but they have lost a lot in the human aspects of life" (S7).

A common statement referring to individualism was: "I think in my country we also believe in the individual's freedom, but the social group is more important. Here, they place the individual as the only and fundamental force that makes everything go around" (S2).

Fifty-five percent of the Costa Rican students did not report any problem with the American time orientation. Forty-five percent did. Regarding time orientation, s7 
said: "I have friends who have airplane tickets to go to an opera play in New York two years from now, and I don't even know what I am going to do in two weeks."

All interviewees were asked what they would consider their most intense problem or the issue that gave them the most trouble adjusting to the American society (Question \#11). There were a variety of answers regarding this matter. To $27 \%$ of the population (3 interviewees), language constituted the most difficult issue in adjusting. Eighteen percent ( 2 interviewees) listed status quo loss as their main problem. Next, there are listed the problems that have been considered as the most problematic issue by only one person (98): finances; ethnocentrism; individualism; high anxiety; homesickness; and relationship with faculty.

In sum, concerning this specific population, the results demonstrate that there is no consensus regarding the most intense adjustment problem faced by Costa Rican students. This means that it is not possible to identify a specific aspect of the American culture to which most Costa Ricans have trouble adjusting. 
CHAPTER V

DATA ANALYSIS

In the previous chapter, the information produced through the interviews was summarized in percentages, within the themes specified in the inventory. In the following chapter these data are interpreted by comparing the outcome of the interviews regarding what Costa Rican students considered to be adjustment problems against the expected adjustment problems drawn from the literature.

Basically, this chapter contains a discussion of the congruence between themes generated in the three stages of data analysis--analysis of the literature review, preliminary survey and personal interview, and the follow-up interviews.

Part of the results are supportive of what has been found in the literature review, another portion of the results proved not supportive, while still another is ambiguous. In general, the results of the follow-up interviews with eleven students tended to be consistent with results from the preliminary survey and in this sense, also supported propositions found in the literature review. Making friends was revealed as a problem by a high percentage of the population (91\%), validating earlier 
findings by Dubois (1956), Harris and Moran (1987), and Smith (1955). As discussed in the literature review, conflict or frustration are very likely to arise if a person from a culture that conceives of friendship in terms of long and intimate relationships lives-temporarily or permanently--in a society that prepares the individual for casual, superficial and compartmentalized types of relationships. In this sense, Costa Rican students reported experiencing problems, which is not surprising due to the fact that they come from a society that prizes intimate and long-lasting friendships, but are living in a society that advocates a more superficial kind of friendship.

In general, the subjects' concern about social interaction with Americans seemed to be consistent with the literature. An explanation of this may be that, as discussed by Gudykunst and Ting-Toomey (1988) (see Chapter II), Costa Rica is a relationally-oriented society. Adjustment problems arise because Costa Rican students like to relate with other people, they are "other-directed" (DuBois, 1956), and therefore feel very uncomfortable when their social advances are not reciprocated by Americans who are "inner-directed" (DuBois, 1956).

As indicated in the results, $82 \%$ of the population reported having difficulties in dealing with the American concept of family. The Costa Rican students' expectations 
regarding what a family is are different from American expectations. An aspect of this complex issue can be seen in the following quote: "Americans do not show the degree of respect for their parents that we do" (S8). So, as it was expected, based upon the discussions mentioned in Chapter II, it is hard for Costa Rican students to deal with the American concept of family, for they are seeking close relationships within the family while in the American culture each member of the family is first of all an individual.

Considering the fact that Latin American cultures are group-oriented, the fact that Costa Rican students have problems with the American competition value orientation is not surprising. That $73 \%$ of the population reports facing problems in regards to the competitive attitude exhibited by Americans supports Harris and Moran's (1987) and Althen's (1988) idea stated in Chapter II, focusing on the competition orientation.

The interviewees highlighted the fact that competition represents one of the most valued qualities in the U.S., but not necessarily in Costa Rica, as explained in Chapter II. Competition is not one of the strongest characteristics of the Costa Rican culture. One interviewee's remark was: "The American competitive attitude is very shocking because in my own culture the spirit of cooperation prevails. . " (S2). 
Supportive of propositions of the literature are the reports by interviewees referring to the difficulties they encountered interacting with their American classmates. Seventy-three percent of the Costa Rican students are not at ease in their relationships with their American counterparts. This is similar to the ideas discussed by Althen (1988) and stated in Chapter II. According to Althen, Americans as students also exhibit manifestations of the individualism dominant in other aspects of their lives. As students, Americans consider themselves as independent and separate individuals, an attitude that conflicts with some of the foreign students' position to the extent that Costa Rican students see themselves as a part of a group, primarily, and therefore, seek closer relationships within the classroom.

Findings show that high anxiety is experienced by $73 \%$ of the Costa Rican student population, which is supportive of Barna's (1985) ideas regarding anxiety as inherent to intercultural experiences. According to Barna (1985), high anxiety is the result of all the problems encountered by strangers in another culture, and it at the same time interferes with the outcome of intercultural encounters. For a statement regarding how Costa Ricans describe this feeling, refer to page 101 of this thesis.

Reports of language as a stumbling block in intercultural settings are consistent with previous 
discussions by Barna (1985), Furnahm (1987), and Kim (1987), reported in Chapter II. According to these authors, strangers including foreign students, need to command the language of the host country not only in order to survive but in order to adjust better to the new environment. Kim (1987) argues that ". . the more competent an immigrant is in the host language, the greater will be his participation in interpersonal communication with members of the host society" (p. 69).

The primary role of language in adjusting is clear. It heavily influences how a foreigner handles his/her relationships in the host society. It is not to be inferred that if a visitor commands the host language the rest of the problems will disappear. However, if that is the case, the sojourner has a powerful tool in his/her hands that could help him or her to understand the new social context. This idea is exemplified by Subject 6's statement:

I felt very frustrated and disoriented when I could not either communicate nor understand what people were telling me. I started feeling better when I was able to communicate with people. However, later I had mixed feelings because even though I was speaking the same language there were many things I could not understand.

Pertaining to touch behaviors, the results corroborated what has been found in the literature. In addition, the percentage of the interviewees who disclosed facing problems regarding this matter (64\%) confirms what 
was expected for Costa Rican students. Reports of uneasiness about tactile behavior by Costa Rican students are similar to Althen's (1988), Gudykunst and Ting-Toomey's (1988), and Shuter's (1976) statements about the issue. In brief, it is hard for Costa Rican students, as a part of a society in which physical contact is not only accepted but liked, to interact in a society in which the individuals keep physical contact to the bare minimum, such as the American society.

Even though some of the interviewees mentioned having problems with their role as students in an American campus, a majority of them (64\%) did not. In this sense, the results do not support what was expected to be a problem for this study's population. There are salient differences regarding what is expected of a student in the U.S. and in Costa Rica, such as a more active role on the part of the American student, meaning more participation, both in and out of class. This researcher cannot speculate on the reasons why the results did not sustain what was supported in the preliminary survey.

Extremely surprising is the fact that the results do not support the ideas from the literature review referring to three of the four nonverbal communication themes. Eye contact, use of time and proxemics are considered not problematic for a majority of the interviewees. As discussed in Chapter II, nonverbal communication is 
determinant in the outcome of intercultural encounters, because each culture has a different silent language that accompanies or substitutes for verbal communication. The importance of nonverbal communication lies in the fact that most of human communication is nonverbal (Althen, 1985; Barna, 1985; Condon and Yousef, 1985; and DeVito, 1985). Pertaining to eye contact, Althen (1988) describes the salient difference between Americans and Costa Ricans. As can be found in the Iiterature review, Costa Ricans are used to looking directly at the person they are talking to for longer periods of time and they usually stare at people. An explanation of why this difference in behavior was not reported as a problem by $82 \%$ of the interviewees is that this issue is so subtle that it is noticed only by very observant people. Another interpretation could be that Americans' patterns of eye contact do not bother Costa Ricans. Most likely, it is more uncomfortable to be stared at than to stare. Costa Ricans' behavior may be more upsetting to Americans. The fact that one of the interactants is uncomfortable is enough to cause a reaction in both. But, as mentioned above, this behavior is subtle to the extent that is not easily recognized by nonobservant people. Perhaps an individual trained in intercultural matters would more quickly identify this phenomenon. 
Although it was expected that the population of this study would face some difficulties adjusting to the American's use of time and pace of life, the results do not confirm this expectation. The literature review extensively discussed the contrasting value differences between the Americans and Costa Ricans regarding this matter. According to discussions in Chapter II, Costa Ricans were supposed to have problems with punctuality and deadlines, as well as with the accelerated pace of life of the American society (e.g., Harris and Moran, 1987). However, that $100 \%$ of the interviewees did not report facing problems about how to manage their time in the U.S. is less supportive of the literature than was anticipated. In addition, the literature refers to the rapid pace of life predominant in the American society as being very hard to cope with by sojourners from cultures in which the pace of life is slower in comparison to the U.S. (Harris and Moran, 1987), but this did not seem to bother Costa Rica students. This is not considered typical Costa Rican behavior according to the literature and this researcher's experience. An interpretation of this could be that Costa Rican interviewees have been told about this characteristic prevalent in the North-American society, and have become more time-conscious, thus avoiding problems in this regard. This assumption could be supported by the following quotes: "In Costa Rica I was told I must be punctual if I wanted to 
avoid serious problems with people and progress academically" (Slø). Subject 3 commented, "In Costa Rica, they told me that in order to succeed in the U.S. I should learn how to do things faster and one after the other. They warned me that leaving things for tomorrow could lead me nowhere."

Reports by the interviewees (73\%) about not having difficulties concerning proxemics are not supportive of the literature review. Eindings in the literature predicted that Costa Ricans would encounter problems when interacting with Americans. What might happen when Costa Ricans interact with Americans is described by Lundberg (1960) in the following quote: "The desire (Costa Ricans') to be physically close sometimes alarms Americans and they tend to back off without realizing that they are so doing" (p. 11$)$

Thus, taking this into account, it is very intriguing that a majority of the Costa Ricans interviewed did not report problems regarding the use of personal distance. Only one explanation fits here. As in the case of the time issue, some of the students remarked on being told about not getting to close to people in the U.S. For example, subject 5 commented that during the pre-departure orientation received in Costa Rica, he or she was told "not to get to close to Americans because they get very uncomfortable." And Subject 7 stated: "At the American 
embassy they told me that it is as if each American is surrounded by an invisible wall and if you try to cross it, they do not like it." So, it seems that to know the differences between Americans and Costa Ricans, regarding proxemics, helped this study's population to adjust better in this sense.

Some of the results seem to be ambiguous, to the extent that there is a slight difference regarding the percentages of interviewees that reported or did not report facing problems in certain areas. On the one hand, in five of the themes--meaningful relationships, phatic communication, materialism, loneliness, and isolation-$55 \%$ of the interviewees disclosed encountering difficulties while 45\% did not. If a higher percentage would show here, these results would prove supportive of propositions in the literature review and of the themes included in the inventory that were followed-up in the interviews. But, because there is not a significant difference, for this study's purposes they are not considered as actually supporting the literature.

On the other hand, in four of the themes followed-up during the interviews--homesickness, relationships with faculty, time orientation, and materialism--55\% of the respondents did not report encountering problems in those areas. Again, these themes as discussed in the literature review by authors such as Althen (1988), Gudykunst and 
Ting-Toomey (1988), and Harris and Moran (1987) were expected to cause some adjustment problems to Costa Rican students. Even though $55 \%$ did not mention them as a problem, a noteworthy minority of $45 \%$ did. So, there is not enough support to say that the results in these respects are not consistent with the literature review.

Some new themes were generated in the interviews that were not incorporated in the original Inventory (see Appendix $B)$. The new themes generated in the final interview phase were:

Status loss

Lack of informal "you" in the English language

Climate

Informality

Honesty

Directness

Deductive thinking style

Americans' ethnocentrism

Showing affection or emotions

Finances

Privacy

Americans' self-sufficiency

Religion

Linear vs. circular comm. pattern

Prejudice

Discrimination 
The new themes are not in the Inventory for three main reasons. The first one is that many of them are not related to values, which is the main focus of this thesis. The second one is that even if they were included in the Preliminary Survey, the responses to that survey did not support their relevance to Costa Rican students. And finally, there are a few that were never taken into consideration. None of the new themes were mentioned as often as themes from the list of expected problems.

Among the themes that were not considered because they are not related to values--the first group--are finances and climate, both mentioned by $27 \%$ of the population. That $73 \%$ did not report problems in either of these respects is inconsistent with the literature, These issues were discussed by several authors in Chapter II. Sharma (1971), for one, considers that foreign students generally face problems regarding finances and climate. However, this seems not to be the case of Costa Rican students.

In the second group, listed by 458 of the interviewees, is the characteristic of showing affection or emotions. This is an example of the common responses that demonstrate these results: "People here are gentle but cold, they do not show affection. For instance, in my country, when you happen to see your friend, you show that person that you are happy to see him or her. In general, I think it is easier for us to show emotions. I really miss 
the warmness of the Tico (Costa Rican)" (S5). But, the fact that $55 \%$ did not report this issue reflects an ambiguity of whether or not these results are supportive of reports in the literature review.

Ethnocentrism was mentioned by $36 \%$ of the population. Concerning this issue, one subject's comment was: "They (Americans) are very closed-minded. They live their own world, they do think it is the best, and what is worse they think everybody has to live the way they do" (S9).

Also, in this second group appears the concept of "privacy," which was seen as a different value, compared to their own culture, by $25 \%$ of the interviewees. One of those three interviewees was offended by the concept of privacy. This interviewee's remark was: "The respect for the individual and his or her privacy is so strong in this society that people are afraid to interact with others for fear of interfering in or disrupting their lives" (Sll). The other two, in contrast, while they found it different from what is considered privacy in the Costa Rican culture, seemed to like it. "I felt the difference, but I like it better. Here nobody gets in anybody else's business" $\mathrm{S} 7$. said.

Each one of the following aspects were mentioned by two of the ten interviewees (18\%): discrimination; use of circular communication pattern on their part; Americans' self-sufficiency; and honesty. In addition, in this second 
group concepts such as prejudice, informality and directness have been considered as problems by only 9 \% of the Costa Rican students interviewed.

Referring to the value of age, $55 \%$ of the Costa Rican students did not report any problems. However, $45 \%$ did, and one comment was as follows: "There is a generational gap in this society. Adults and young people cannot communicate. I am used to interacting with older people and here I haven't been able to do it" (Slø). Another subject disclosed: "One thing that really bothers me is the way Americans treat elderly people. To me it is very painful to see how they send their parents and grandparents to a nursing home and nobody cares for them" (S5). The "doing", value orientation was mentioned by $27 \%$ of the interviewees, while $73 \%$ did not talk about it. One subject included in the $27 \%$ of the interviewees who talk about this issue indicated: "American people are frenetic about doing things. They feel that they are worthy only if they are doing something. Americans never have time to enjoy life. We (Costa Ricans) tend more toward personal relations. Even if we have things to do we 'make' time for others" (S8).

Forty-five percent of the interviewees recognized that their non-linear, deductive communication style (meaning the communication manifestation of the pattern of reasoning used by Latin American people) constituted a problem for 
them. Statements that support this idea were: "I used to have problems in writing my papers because I used to approach issues going from the general to the specific, and I touched upon issues as a whole while professors expected me to discuss in depth in maybe one aspect of the entire issue" (S2). "I had communication problems in class in terms of the way I think and express myself. To my classmates I wasn't clear. They always asked, 'but what is your point?.' Later, I realized that we think in a different way" (Slø).

Finally, in the third group, the results are that just 98 of the interviewees stated having problems in the following areas: lack of familiar or informal 'You' in the English language, religion, and loss of status. It was interesting that the students brought up some issues that were in fact mentioned in the Literature Review, but that are not part of the specific inventory used in this study, and some that were never found in the literature concerning foreign students' adjustment problems.

Table I contains all the adjustment problems reported by Costa Rican students. These problems have been classified in terms of how supportive they are of the ideas stated in the literature review. 
TABLE I

SUMMARY OF THE ADJUSTMENT PROBLEMS

FACED BY COSTA RICAN STUDENTS

\section{SUPPORT IVE}

Making friends

918

Social interaction with Americans

$82 \%$

Family relations

$82 \%$

Relationships with classmates

738

High anxiety

Competition

738

Language

$73 \%$

Touch

\section{NOT SUPPORTIVE}

Use of time

Eye contact

Proxemics

Pace of life

\section{AMBI GUOUS}

Meaningful relationships

Phatic communication

Lone liness

Isolation

$55 \%$

Materialism

$55 \%$

Relationships with faculty

Time orientation 


\section{DEMOGRAPHIC DATA ANALYSIS}

The demographic data analysis has been done based upon the following characteristics: sex (male, female); age $(2 \emptyset-3 \emptyset, 31-4 \emptyset)$; academic status (graduate, undergraduate); area of study (social science, general science); and stay period (two years or less than two years, more than two years).

In regards to the first characteristic, it seems that there are some problems that are more intensely felt by females than by males. For instance, the student's role theme is a problem to the $66.66 \%$ of the females while it is mentioned by only $12.5 \%$ of the males. This discrepancy may be because within the Costa Rican culture the students play a more passive role in the classroom, and the responsibility for how a student does is shared with the professor. Also, Costa Rican students typically enjoy close relationhips among themselves and are cooperative with one another. So, based upon this frame of reference, Costa Rican females found their role as students in the American culture to be a problem.

According to the interviewees, it is hard for them "to be in a classroom where one not only feels the individualism that prevails among the students but also have to see how it is preached by the professor in so many ways." (SI) In addition, one can speculate that this is a severe problem for females because they are taught and 
expected to be more group and people oriented, and more dependent, according to the Costa Rican value system. The individualism present in the American culture seems to bother Costa Rican women more than it bothers Costa Rican men. The percentages are $10 \emptyset$ for females and 37.5 for males. The interpretation for this is in the previous paragraph.

While $66.66 \%$ of the female interviewees reported homesickness to be a problem, only $37.5 \%$ of the males did so. This issue could be related to another problem, which is the difference between American and Costa Rican concepts of the family, which posed problems to lobo of females in the population. It constitutes a problem, also, to $75 \%$ of the men. Even though the male's percentage is high, there is a difference of $25 \%$.

One possible explanation for this is the women's role in the Latin American society, in this case the Costa Rican culture, which places them in a very important position in the family. That role allows them to experience in a fulfilling manner the life of the extended family. Also, for some of them, this might be their first time out of their country, which makes them to feel even more homesick. There is also a significant difference in the case of the orientation toward "doing." According to the results, $66.66 \%$ of the women have problems adjusting to the busy and always-in-a-hurry American lifestyle, against to $12.5 \%$ of 
the males reporting this as a problem. The reason for this again could be the passive role that women play in the Latin American societies, including Costa Rica. Another possible reason, however, could be that Costa Rican cultural values made male interviewees less likely than their female counterparts to recognize or admit this problem. In general, women have a slower pace of life. One could say that this is changing in the Latin American culture, in some countries more than in others; but it seems that the traditional role of the women in those societies is still showing in this study's results.

The major difference that appeared in the results of the interviews regarding adjustment issues that were more problematic to males was the "relationship with faculty" theme. The results showed that $62.50 \%$ of the males disclosed having problems in regards to that matter while only 33.33 of the females did.

These results are not surprising if one considers that Costa Rican male and female students held different expectations regarding their relationship with professors. In Costa Rica, the relationship between male students and their professors at the college level, and particularly if the professor is a male, is expected to go beyond the classroom to a more personal level, sometimes even real friendship. Professors and students go after class to talk and discuss different subjects informally over a cup of 
coffee or a glass of beer, depending on the hour the class is held. Interviewees resented Americans' generally strict observation of the professional "teacher-student" relationships. One interviewee remarked: "Here, we are professor and student, but never friends." (SI6)

Pertaining to the second category--age--it looks as if people in the second age group $(31-4 \emptyset)$ experience some of the problems in a more intense way. Sixty percent of the interviewees who are a part of this group reported having problems adjusting to the role that students play in the American college environment. None of the Costa Rican students included in the $2 \emptyset-3 \emptyset$ year group mentioned this theme as a problem. An explanation for this could be the same as the one included in the female category, for this age group incorporates the women who indicated having problems in this area.

Another theme that seems to bother the older portion of this population is "meaningful relationships." While $80 \%$ of older students mentioned this problem, only $33.32 \%$ of the younger people did. This matter does not warrant further interpretation other than to point out that older individuals have been exposed to warmer and closer interpersonal relationships for a longer period of time, in their own cultural environment, in comparison to younger people. 
Language was reported as a problem by $80 \%$ of people in the 31-40 years category, against $50 \%$ of the people in the $26-3 \emptyset$ years group. It is well known that it is easier for younger people to learn another language than it is for older individuals. In the case of this study's population, a majority of the older students learned the English language very recently, and even some of them studied English here, after their arrival, according to their stories.

Finally, the age theme is also troublesome to students between 31 and 40 years. Eighty percent of those students disclosed having problems in adjusting to the age value present in the American society, while only $16 \%$ of the interviewees between $2 \emptyset$ and $3 \emptyset$ years did. This issue is not surprising if one takes into account the high value that Americans place on youth, as has been discussed in Chapter II. According to the interviewees, they can feel that there is a generational gap and they are bothered by the way in which Americans treat elderly people. The results show that people in the $2 \emptyset-3 \emptyset$ years group only mentioned two problems more often than those in the older group. These two problematic themes are: touch $(83.30 \%$ against $4 \emptyset \frac{\circ}{\circ}$ in the other group) and time orientation (66:64\% against $20 \%$ reported by older students).

Regarding touch, it could be normal for younger people to experience more difficulties in this matter, but, Costa 
Ricans in general are expected to face problems in this area, because, as has been stated elsewhere in this thesis, touching is common behavior in Costa Rica. In this researcher's experience, younger people have a tendency to touch more often than older people. Therefore, if people with a strong tendency to touch interact in a society in which physical contact among people is not a generalized custom, problems are expected to arise.

Referring to time orientation, the case is similar to the one discussed above. Latin American cultures including the costa Rican culture, are present-oriented. Individuals from these cultures encounter problems when they 1 ive in a society that is basically future-oriented. The younger Costa Rican interviewees tend to live in the present and worry less about the future, reporting more problems with this theme.

In the third category--academic status--undergraduate Costa Rican students seemed to face more trouble in some themes than graduate students did. Relationships with students, loneliness, social interaction with Americans, high anxiety, and family were themes reported as problems by $10 \emptyset \%$ of the undergraduate students. The same issues were mentioned by $62.50 \%, 37.50 \%, 75 \%, 62.50 \%$ and $75 \%$ of the total of graduate students, respectively.

All these themes that were somehow more problematic to undergraduate students seem to be interrelated. The main 
cause of the problem could be that is harder for these students to penetrate the big mass that constitutes the undergraduate American population. The large number of people in the undergraduate classrooms makes it more difficult for Costa Rican students to establish more personal relationships with American students. This situation makes them feel more lonely, limits their social interaction, and causes more anxiety in them. Generally, at the graduate student level, the classes are composed of fewer students, which makes it easier for Costa Rican graduate students to interact with their American counterparts.

The only problem that is more frequently reported by graduate students is dealing with the time orientation concept. This theme was cited by $62.50 \%$ of the total of graduate students, while none of the undergraduate students mentioned it. Here, the same interpretation can be applied as was applied in the age category, for the majority of the people in the graduate group are the same as those in the $2 \emptyset-3 \emptyset$ years group of that category.

An analysis of the demographic data shows that, regarding the area of study--the fourth category--there seem to be significant differences in the problems students face. In general terms, students in the social science areas encounter more problems than students in the science field do. 
Social interaction with Americans, friendship, meaningful relationships, high anxiety, materialism and family are themes reported as problematic by $100 \%$ of the Costa Rican students pursuing social science careers. The same themes were mentioned by the following percentages of the total of the students in science areas: $71.40 \%, 80 \%$, $28.56 \%, 57.12 \%, 28.56 \%$ and $71.40 \%$, respectively. Two more themes--individualism and age--were stated by $75 \%$ of the Social Science students, while the same themes were mentioned only by $42.84 \%$ and $28.56 \%$ of the science students, in that very order.

One explanation for these results is that, generally, individuals in the social fields of study are more people oriented and have a humanistic educational background that motivates them to interact and get to know people in the host culture. That may be where the problems arise. It is very possible that students who come from a culture that is a people-oriented culture and whose educational background reinforces that characteristic will encounter problems adjusting to a culture such as the American culture in which personal relations and the world view are very different from their own. People in science areas of study are more individualistic and less people-oriented, in general. They deal more with numbers, facts, and the like, and care less about human interaction. 
This generalization is similar to that of DuBois:

In the case of students who are mature, who are concerned with sciences or laboratory techniques that do not rimarily depend upon English, and who have no strong personal needs to relate themselves to a wide social environment, the command of English is not so urgent as for a student of sociology who is gregarious and anxious to 'feel the pulse'

of our national life. (1956, p. 83)

Students in the science field faced two problems that seemed to be more severe to them than to students in social science areas. One is the competition orientation that prevails in the American society. This theme was disclosed by $85.68 \%$ of the students in science and by $50 \%$ of the students in social science areas. The other theme is time orientation, which was mentioned by $71.40 \%$ of the students in the science field while it was not mentioned by any of the students in the social science area.

It seems that competition and future orientation are dominant characteristics of the science careers, and competition, planning, working for the future, and thinking ahead appear to be inherent aspects of these careers' perspectives. Costa Rican students focusing in these areas may face severe adjustment difficulties because their culture has not provided them with the same attitude toward these issues. Competition and future orientation are value orientations that are not at the core of the Costa Rican culture.

Stay period is the fifth category considered in the demographic data analysis. This category has been 
subdivided into two groups. One group is composed of the individuals who have been in the U.S. up to two years, while the second group includes all the individuals who have been living in this country for more than two years. Obviously, the intensity of the problems for students who have been living here for just two years or less is greater than that of the students who have been living in the U.S. for longer periods of time. This seems to be the case regarding the following themes. In reporting these results, the figures inside of the parentheses correspond to the responses of the people who have been living here for more than two years.

Relationship with faculty was reported by $75 \%$ of the population in the first group (42.84\%). The problem of making friends was indicated by $100 \%$ (85.68\%). Dealing with the personal space concept was more difficult to $50 \%$ (14.28\%). Touching behavior was more troublesome to $75 \%$ $(57.12 \%)$. The other three themes were materialism, social interaction with Americans and language, reported as problems by $75 \%(42.84 \%), 100 \%(85.68 \%)$ and $75 \%(57.12 \%)$ of the interviewees, respectively.

It seems normal that students in the two years or less category still experience severe difficulties dealing with some values, behaviors or customs of the host culture. It is possible that some of the students still act according to their own frame of reference, the one they acquired 
during their primary socialization (Berger and Luckman, 1967). Earlier in their stay, the students do not know what to expect or how to behave. They need time to get to know the American cultural milieu and even more time to adjust to it. As it could be expected, students who have been here for a longer period of time seemed to be better adjusted.

The data mentioned above was gathered by doing an analysis between the demographic data of the population under study and the themes contained in the inventory of expected problems of Costa Rican students. The following are the results of an analysis of the new themes that emerge from the interviews and the demographic data. The new themes have been examined as a unit for this analysis. Only two demographic aspects--sex and age--seemed to provide interesting data when analized in conjuction with the new themes.

Referring to sex, in general terms, men encountered more adjustment problems than women did. While $55.88 \%$ of the additional themes were mentioned by men, $44.12 \%$ were reported by women.

The point here is that the male's percentage is slightly higher than the female's percentage, and, in addition, males constitute $72.8 \%$ of the total of the interviewees while females are $27.2 \%$ of that population. 
It would be interesting to know what the results look like with a more balanced population.

With respect to the age element of the demographic data, the population is made of two groups. One group includes people between $2 \emptyset$ and $3 \emptyset$ years, constituting $54.55 \%$ of the population. In the other group, there are people between the ages of 31 and $4 \emptyset$, representing $45.45 \%$ of the total of the interviewees.

The first group reported encountering $26.47 \%$ of the new problems, while the second group indicated facing a total of $73.53 \%$ of them. One can infer from the above-mentioned data that the older the sojourners the more problems they faced. This could be interpreted as meaning that it is harder for older people to adjust to a new culture.

According to DuBois (1956) "the age of a foreign student is generally assumed to be an important factor in his adjustment" (p. 85). Additionally, Kim (1977) relates two variables--age and language--which play a relevant role in adjusting to another culture. This author's discussion is as follows:

- . age at the time of immigration was found to be another important factor which affects the immigrant's language competence. The younger an immigrant was at the time of immigration, the greater competence he developed in the host language. (p. 74)

A final comment here is that older people also are able to identify more complex types of problems, such as 
differences in communication patterns, reasoning style and the ethnocentric attitude of American people. 
CONCLUSIONS, LIMITATIONS, APPLICATIONS

AND EUTURE RESEARCH

\section{CONCLUSIONS}

Several authors suggest that the problems of foreign students are to a large extent the same as those of all students. This may be true to the extent that students everywhere encounter problems such as achieving academic goals, gaining acceptance, and the pressure and anxiety related to school work. However, it is this researcher's contention that there are additional problems related to cultural differences faced by foreign students.

There are problems inherent in being a foreigner: problems unique to foreign students. The literature review revealed that the very fact of being a foreigner brings high anxiety. Therefore, there are extra or more severe adjustment problems that foreign students encounter in addition to those of simply being a student. Even the problems that are encountered by all students are typically magnified for foreign students, according to the degree of difference between their nature cultural values and those values encountered in their host country.

One difference between Costa Rican students and American students is that the former must learn the 
American cultural maze. Host national students, regardless of the country involved, know almost everything--where to look for what they need, how to behave, what to expect from the professors, what is expected of them. In short, the host national students are specialists on their own culture. Foreign students, instead, have to learn the cultural milieu of the country they are visiting. ". . Until he learns the cultural equivalent of Basic English, he [the foreign student] is handicapped indeed" (Smith, 1955, p. 234). Foreign students--Costa Ricans, in the case of this thesis--come to the U.S. with the goal of achieving an academic degree, but unless they are able to communicate effectively and have a fulfilling everyday life, they cannot concentrate on their studies.

Learning a culture is not an easy process. It has been discussed in this thesis that to adjust to a new culture strangers usually undergo several phases that start before leaving home and continue throughout the sojourn, even after the visitors return home. As suggested in the literature review, some of these stages are hard to overcome for some individuals, as they suffer reentry culture shock.

This study's focus coincides with Smith's (1955) arguments in the sense that, in order to achieve their main goal, foreign students have to come to terms with the American culture first. This is why this thesis' main 
purpose was to examine the adjustment problems of Costa Rican students from an intercultural perspective, rather than to study the traditionally expected problems of foreign students, which potentially can be solved after they learn the intricacies of the host culture.

Differences in value systems appear to be the kind of difficulties that are not easily solved and sometimes bother the sojourners during their entire stay. One main conclusion of this study is that even though adjustment problems reported by Costa Rican students are generally the same as those mentioned in the literature, the causes of these problems may be unique to Costa Ricans due to the specific differences in value systems between Costa Rica and the U.S.

Widespread in the literature is the assumption that interpersonal relations are fundamental in the adjustment process of foreign students. From this study's findings, it is plausible to assert that interpersonal relations are of prime importance to the Costa Rican students, too. Like many foreign students, Costa Rican students are oriented toward more intense interaction with others. Costa Ricans find it difficult to adjust when they realize that they do not have their friends' and families' support.

Some of the Costa Rican students' adjustment problems stem from the lack of social contact. It has been discussed earlier in this research that the American 
society does not promote interpersonal interaction.

Characteristically, for example, classmates are less

sociable and personal than Costa Rican students expect them to be.

In general terms, it is extremely interesting to find out that five of the eight most supported themes regarding adjustment problems, in this study, were relational issues such as relationships with classmates, establishing friendships and family relations, as above mentioned, as well as social interaction with Americans, in general, and competition.

The results of this study lead to the conclusion that, in general, there is a lack of knowledge of the American culture on the part of the costa Rican students, which is the cause of frustration and disorientation that could have a negative effect on their adjustment. But, on the other hand, there is a tendency among costa Rican students to adjust better to those few aspects of the American culture they know about.

If one considers Brislin's definition of adjustment in terms of feeling at home and experiencing a sense of belonging, one can say that Costa Rican students are not well-adjusted to the American culture. They disclosed that they do not feel at home in the United States and that they do not see themselves as a part of this society. As an answer to the last question of the interview schedule 
(Comments...), a majority of the interviewees indicated a strong desire to go home as soon as they finish their academic programs. According to them, they would not change what they called the spiritual quality of life that they have in Costa Rica for the better but also more materialistic quality of life of the United States.

\section{LIMITATIONS}

The central limitation of this thesis is the fact that there are few specific references in the literature concerning the Costa Rican values, a scarcity necessitating the use of a wider criterion (Latin American values), on which there exists more information in the intercultural communication literature.

A methodological pitfall of this study is that it is a description and self-perception of the situation of the Costa Rican college students. According to Taylor and Bogdan (1984), one of the disadvantages of the interview is that what an individual discloses during the interview is not necessarily what he/she would say under other circumstances.

In addition, this thesis lacks the observation methodological technique that is recommended to accompany interviews in a qualitative type of study. The interviewer --in this case, the researcher--did not have the opportunity to observe the Costa Rican students directly, on a day-to-day- basis. Therefore, the interview lacked 
the context that would allow better understanding of how Costa Rican students adjust to the American culture from their own perspectives.

Another limitation is that the subjects of this study are a specific Costa Rican student population--students located in Oregon--and not a larger sample, to which the researcher does not have access. Even though the study's population may be considered a typical representation of the Costa Rican culture, it is not sufficient to make generalizations from this thesis' final outcome.

In that sense, it would be better to interview a larger, random sample that would allow the researcher to generalize the results, and to say that those could be classified as the adjustment problems that Costa Ricans in general would face in the United States. A potential population for a future research could be Costa Rican people studying all over the U.S. However, in spite of this limitation, it is appropriate to note that, in a qualitative, preliminary study such as this, the contribution that each participant could provide to the research in general is more important than the size of the population.

Another shortcoming is that the study will take into account just the students' experience during their visit to the U.S., and not issues such as their pre-arrival and re-entry experiences, which, although interesting because 
they are part of the general adjustment process they go through, are not possible to discuss here.

The main limitation, however, is the variety of time spans of the students living in the U.S. This makes a difference because their experience, their perception about themselves, and their attitudes toward the host culture vary significantly. It is possible that the costa Rican students who have been here for longer periods of time tend to forget their experiences, the first things they had to adjust to, or the issues that caused some trouble in their lives as visiting students.

APPLICATIONS FOR FUTURE RESEARCH

A potential application of this study is to design a training program for future Costa Ricans coming to the U.S., based on the results of this thesis, that will better suit this population's needs in adjusting to the American culture. There are two main reasons to suggest the potential value of a specific training program, focusing on value differences between the Costa Rican and American cultures. First of all, the expectations theory (Weissman and Furnham, 1987) (refer to Chapter II) was confirmed to a certain extent when Costa Rican students reported not encountering problems in those aspects of the American culture they knew about prior to departure.

The second reason is the need to teach costa Rican students to be interculturally sensitive. According to 
Bennett (1986), of prime importance in intercultural

communication is the concept of "difference". It has been discussed earlier that the differences between the sojourners' culture and the hosts' culture is what provokes problems in intercultural communication and therefore in adjustment. However, Bennett (1986) suggests that ways of dealing with differences can be considered on a developmental continuum moving from "ethnocentrism" to "ethnorelativism."

Ethnorelativism implies that if people are able to recognize, accept and adapt to differences, they will be able to move from an ethnocentric perspective, in which one's own values, norms, behaviors and customs are considered the only way and sometimes the best way, to a state of intercultural sensitivity, in which one is better able to deal with differences.

The goal of the training program suggested here is not to acculturate or "Americanize" Costa Rican students. The issue is not to replace the Latin American value system with the American system, but to "educate" Costa Rican students in such a way that the result will be students with a new perspective. Thus, the purpose of this training program will be to start building a bicultural perspective in the Costa Rican students that will better equip them to deal with differences. Once they know the differences, 
adjustment may proceed more smoothly and the larger goal of international educational exchange may be better served.

Future research might be designed to discuss the expectations of Costa Ricans before they came to the U.S. and their experiences here, in order to see in what way, if any, their expectations specifically influence their experiences and their adjustment process.

As mentioned before, it would be interesting to conduct this research at a national level, in order to collect the quantity of statistical data that would allow generalization of the findings on adjustment problems faced by Costa Rican students in the U.S. An important side of this same research could be to interview all the Costa Rican students who have returned home before finishing their programs. Another topic worthy of additional study is the question of whether or not all visiting Costa Rican students actually recognize the cultural differences which may be at the root of their adjustment problems. A researcher might ask if the differences are important to them and, if so, if these differences are perceived as negative or positive factors in their adjustment.

Also, it would be relevant to study Costa Ricans' preexisting attitudes toward Americans before leaving Costa Rica to see if in any way they influence their later adjustment. An intriguing research could be to study what positive and negative personal skills and traits Costa 
Rican students possess that would help them in their adjustment or make it even more difficult.

Regarding the adjustment process and the curves of adjustment, no specific data was collected from this study. Hencefore, another study should attempt to determine the intensity with which Costa Rican students experience the adjustment process described in the Literature Review. One can speculate they went through an adjustment process similar to the one described in Chapter II. However, a specific study could focus on the intensity with which Costa Ricans undergo the mentioned phases of adjustment, and how long it takes them to adjust to the American culture. Such a study might reveal more information about how Costa Rican students in the United states cope with the adjustment problems they almost inevitably face. 
REFERENCES

Adams, G. R., \& Schvaneveldt, J. D. (1985). Understanding research methods. New York \& London: Longman.

Adler, P. S. (1975). The transitional experience: An alternative view of culture shock. Humanistic Psychology, 15 (4), 13-23.

Althen, G. (1988). American ways. A guide for foreigners in the United States. Yarmouth, ME: Intercultural Press, Inc.

Barahona, L. (1975). El gran incognito. San Jose, Costa Rica: Editorial Costa Rica.

Barna, L. M. (1985). Stumbling blocks in intercultural communication. In L. Samovar and R. E. Porter, Intercultural communication: A reader (4th ed.). Belmont, CA: Wadsworth Publishing Company.

Barnlund, D. C. (1985). Communication in a global village. In L. A. Samovar and R. Porter (Eds.), Intercultural communication: A reader (4th ed.). Belmont, CA: Wadsworth Publishing Company.

Bennett, J. (1977). Transition shock: Putting culture shock in perspective. International and Intercultural Communication Annual, IV, 45-5I.

Bennett, M. (1986). Towards Ethnorelativism: A developmental model of intercultural sensitivity. In M. Paige (Ed.) Cross cultural orientation. Lanham, MD: University Press of America.

Benson, P. (1978). Measuring cross-cultural adjustment: The problem of criteria. In R. Brislin, Crosscultural encounters (3rd ed.). New York: Pergamon Press.

Berger, P., \& Luckmann, T. (1967). The social construction of reality. New York: Anchor. 
Biesanz, K. Z. (1985). The Costa Ricans. Englewood Cliffs, NJ: Prentice-Hall.

Brein, M., \& David, K. (1971). Intercultural communication and the adjustment of the sojourner. Psychological Bulletin, 76, 215-230.

Brislin, R. (1981). Learning styles. In G. Althen (Ed.), Learning across cultures. Washington, D.C.: NAFSA.

Brislin, R. (1984). Cross-cultural encounters (3rd ed.). New York: Pergamon Press.

Brislin, R. (1986). Intercultural interactions. A practical guide. Beverly Hills, CA: Sage.

Byrnes, F. (1966). Role shock: An occupational hazard of American technical assistants abroad. Annals of the American Academy of Political and Social Science, 368, 95-168.

Clarke, H., \& Ozawa, M. (1970). The foreign student in the United States. Madison, WI: School of Social Work, The University of Wisconsin.

Condon, J. C. (1985). Good neighbors. Yarmouth, ME: Intercultural Press, Inc.

Condon, J. C., \& Yousef, F. (1987). An introduction to intercultural communication (lith ed.). New York: Macmillan Publishing Company.

David, K. (1972). Intercultural adjustment and applications of reinforcement theory to problems of "culture shock." Trends, $\underline{4},(3), 1-64$.

Deutsch, S. E., \& Won, G. Y. M. (1963). Some factors in the adjustment of foreign nationals in the United States. The Journal of Social Issues, XIX (3), 115-124.

DeVito, J. A. (1985). Human communication (3rd. ed.). New York: Harper and Row, Publishers.

DuBois, C. (1956). Foreign students and higher education in the United States. Washington, D.C.: American Council on Education. 
Furnham, A., \& Bochner, S. (1982). Social difficulty in a foreign culture: An empirical analysis of culture shock. In S. Bochner (Ed.), Cultures in contact. Studies in cross-cultural interaction. Oxford: Pergamon.

Eurnham, A., \& Bochner, S. (1986). Culture shock:

Psychological reactions to unfamiliar environments. New York: Methuen.

(Furnham, A. (1987). The adjustment of sojourners. In Y. Y. Kim \& W. B. Gudykunst. (Eds.) Cross-cultural adaptation. International and intercultural Communication Annual, XI, 42-61.

Gama, E., \& Pedersen, P. (1977). Readjustment problems of Brazilian returnees from graduate studies in the United States. International Journal of Intercultural Relations, $1(4), 46-59$.

Glaser, B. G., \& Strauss, A. L. (1967). The discovery of grounded theory. New York: Aldine de Gruyter.

Glend, E. S. (1982). Man and mankind (2nd ed.). Norwood, NJ: Ablex Publishing Corporation.

Golden, J.S. (1971). Student adjustment abroad: A psychiatrist's view. International Educational and Cultural Exchange, VII, (2), 28-36.

Gorden, R. L. (1976). Living in Latin America. Lincolnwood, IL: National Textbook Company.

Graber, D. A. (1984). Processing the news. New York\& London: Longman.

Gudykunst, W.B., Wiseman, R., \& Hammer, M. (1977). Determinants of sojourners' attitudinal satisfaction. In B. Ruben (Ed.), Communication Yearbook I. New Brunswik, NJ: Transaction.

Gudykunst, W. B., \& Hammer, M. R. (1987). Strangers and hosts. In Y. Y. Kim and W. B. Gudykunst (Eds.) Cross-cultural adaptation. International and Intercultural Communication Annual, XI, 106-139.

Gudykunst, W. B., \& Ting-Toomey, S. (1988). Cultural and interpersonal communication. Beverly Hills, CA: Sage Publications, Inc. 
Gullahorn, J. T., \& Gullahorn, J. E. (1963). An extension of the U-Curve hypothesis. The Journal of Social Issues, XIX (3), 33-47.

Guthrie, G. (1975). A behavioral analysis of culture learning. In R. W. Brislin, S. Bochner, \& W. J. Lonner, Cross-cultural perspectives on learning. New York: Wiley Halsted.

Johnson, D. C. (1971). Problems of foreign students. International Educational and Cultural Exchange, VII $(2), 61-68$.

Kahne, M. J. (1976). Cultural differences: Whose troubles are we talking about? International Educational and Cultural Exchange, $X I(4), 36-4 \varnothing$.

Kim, Y. Y. (1977). Communication patterns of foreign immigrants in the process of acculturation. Human Communication Research, $\underline{4}(1), 66-77$.

Kim, Y. Y. (1977). Inter-ethnic and intra-ethnic communication: A study of Korean immigrants in Chicago. International and Intercultural Communication Annual, $\underline{4}, 53-68$.

JKluckhohn, F., \& strodtbeck, F. (1961). Variations in value orientations. Evanston, IL: Row, Peterson.

Kohls, L. R. (1984). Survival kit for overseas living (2nd ed.). Yarmouth, ME: Intercultural Press, Inc.

Lainer, A. R. (1981). Living in the U.S.A. (3rd ed.). Chicago, IL: Intercultural Press, Inc.

Lascaris, C. (1977). El costarricense (2nd ed.). San Jose, Costa Rica: Editorial Universitaria Cent roamericana.

$\checkmark$ Lewis, T. J., \& Jungman, R. E., (Eds.) (1986) . On being foreign. Yarmouth, ME: Intercultural Press, Inc.

Levine, R. (1985, March). Social time: The heartbeat of culture. Psychology Today, 19(3), pp. 29-35.

Lofland, J., \& Lofland, L. H. (1984). Analysing social settings (2nd ed.). Belmont, CA: Wadsworth Publishing Company. 
Lundstedt, S. (1963). An introduction to some evolving problems in cross-cultural research. The Journal of Social Issues, XIX (3), 1-9.

Lysgaard, S. (1955). Adjustment in a foreign society: Norwegian Fulbright grantees visiting the United states. International Social Science Bulletin, VII, 45-51.

Marden, C., \& Meyer, G. (1968). Minorities in America. New York: Van Nostrand Reinhold Co.

Mestenhauser, J. A. (1969). Foreign students in the American milieu. Paper presented at the NAFSA's meeting in Madison, Wisconsin.

Oberg, K. (1972). Culture shock and the problem of adjustment in new cultural environments. Readings in Intercultural Communication, II, 43-45.

Pearce, W. B., \& Kang, K. W. (1987). Conceptual migrations. Understanding "Travelers' tales" for cross-cultural adaptation. International and Intercultural Communication Annual, XI, 2ø-41.

Porter, R. E., \& Samovar, L. A. (1985). Approaching intercultural communication. In L. A. Samovar, and R. E. Porter (Eds.) Intercultural communication: A reader. Belmont, CA: Wadsworth Publishing Company.

Porter, J. W. (1962). The development of an inventory to determine the problems of foreign students. Unpublished doctoral dissertation. Michigan State University, Michigan.

Pruitt, F. J. (1978). The adaptation of African students to the American society. International Journal of Intercultural Relations, 2 (1), 9ø-116.

Selltiz, C., \& Stewart, W. C. (1962). Factors influencing attitudes of foreign students towards the host country. Journal of Social Issues, 18, (1), 7-55.

Sermol, D. (1983). Toward a phenomenological-based perspective of acculturation with application to Scottish immigrants. Unpublished master's thesis, Portland State University, Oregon. 
Sharma, S. (1971). A study to identify and analyze adjustment problems experienced by foreign nonEuropean graduate students enrolled in selected universities in the state of North Carolina.

Unpublished doctoral dissertation, University of North Carolina.

Schild, E. O. (1968). The foreign student, as stranger, learning the norms of the host-culture. Journal of Social Issues, $188(1), 41-54$.

Schuetz, A. (1944). The stranger. American Journal of Sociology, 49, 599-607.

Shuter, R. (1976). Proxemics and tactility in Latin America. Journal of Communication, 26, (3), 46-52.

Smith, H. W. (1975). Strategies of social research. Englewood Cliffs, NJ: Prentice-Hall, Inc.

Smith, M. B. (1955). Some features of foreign-student adjustment. The Journal of Higher Education, XXVI (5), 231-241.

Spaulding, S., et al. (1976). The world's students in the United States: A review and evaluation of research on foreign students. New York: Praeger Publishers.

Stewart, E. C. (1985). American cultural patterns (13th ed.). Yarmouth, ME: Intercultural Press, Inc.

Stewart, E.C. (1969). Cultural assumptions and values. In E. C. Stewart, et al., Stimulating Intercultural communication through role playing. Washington, D.C.: The George Washington University Human Resources Research office.

Szalay, L. B., \& Inn, A. (1987). Cross-cultural adaptation and diversity: Hispanic-Americans. In Y. Y. Kim \& W. Gudykunst (Eds.) Cross-cultural adaptation. International and Intercultural Communication Annual, XI, 212-232.

Taylor, S. J., \& Bodgan, R. (1984). Introduction to qualitative research methods (2nded.). New York: John Wiley and Sons.

Tucker, R. K., Weaver, R. L., \& Berryman-Fink, C. (1981). Research in Speech Communication. Englewood Cliffs, NJ: Prentice-Hall, Inc. 
Tyler, V. L. (1987). Intercultural interacting (2nd ed.). Provo, UT: DavidM. Kennedy Center for International Studies, Brigham Young University.

Veroff, J. (1963). African students in the United States. The Journal of Social Issues, XIX(3), 48-60.

White, W. F., \& Holmberg, A. R. (1956). The contrast of cultures: US \& Latin Americans. Human Organization, $1-24$.

Weissman, D., \& Furnham, A. (1987). The expectations and experiences of a sojourning temporary resident abroad: A preliminary study. Human Relations, 4פ(5), 313-326. 
APPENDIX A

QUEST IONNAIRE 
QUESTIONNAIRE

General Data

1. How long ago did you enter the United States of America?

From $\emptyset$ to 3 months

From 3 to 6 months

From 6 to 12 months

From 12 to 18 months

From 18 to 24 months

More than 24 months

2. Have you lived and/or studied before in the U.S.?

Yes

No

3. If the answer to the previous question is yes,

for how long?

Less than a month

From 1 to 3 months

From 3 to 6 months

From 6 to 12 months

From 12 to 24 months

More than 24 months 
4. Have you stayed in another country, other than your native country for a period longer than three months?

Yes

No

5. If your previous answer is yes, list the country or countries you have visited:

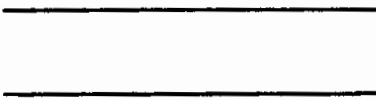

6. Did you have a good command of the English language before you left Costa Rica?

Yes

No

7. If you have received your English training in the U.S., how much did you know before you started?

Nothing

A little bit

A $10 t$

Enough More than enough

8. How Iong have you being studying or have you studied English?

From $\emptyset$ to 3 months

From 3 to 6 months

From 6 to 9 months

More than 9 months

9. Sex :

Male Female

10. Age:

Under $2 \emptyset$

From 20 to 25

From 25 to 30 
From $3 \emptyset$ to 35

over 35

Orientation

11. Did you receive any kind of orientation about the American culture before you left Costa Rica?

Yes

No

12. If yes, how satisfied are you with the orientation? None Somewhat

Moderately Very much

13. How useful has that information been to you during your stay in this country?

None Somewhat

Adequately Very much

14. Have you received any formal orientation about the American culture while you were here?

Yes

No

15. If yes, how long after your arrival?

One week

Two weeks

A month

Two months

More than two months 
16. What information not included in that orientation do you think would be useful to get around well in the U.S.?

Explain:

Differences and Similarities

17. In your opinion, are there significant differences between American culture and your own?

Yes

No

18. If Yes, did you expect to find these differences? Yes No

19. What are the main differences that you observed?

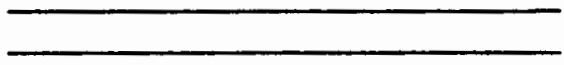

20. Do you think that there are similarities between the two cultures?

None at all

A few

Some

A lot

21. If yes, please list the main ones? 
22. Rank in order of importance the areas in which you have encountered difficulties:

( 1 is the most important, 8 is the least)

Language

Academic problems

Interpersonal

relations (with

(with professors,

class-mates,

Americans in general...)
Cultural differences

Health

Economic problems

Hous ing

23. Have you faced problems studying in the American educational system, where the students play a more active role than they do in Costa Rica?

Yes

No

24. Have you noticed that while the American reasoning style is inductive (from the particular to the general), the Latin American one is deductive (from the general to the particular)?

Yes

No

25. Do you think that this has affected your studies? Yes

No

26. You would attribute any problems, past or present, in your studies mainly to: (You may check more than one).

Language

Differences in reasoning style

Use of time

All

None 
others (Specify):

27. Do you have or have you had any difficulty interacting with:

Professors

Students

University staff

A 11

None

28. If yes, to what you would attribute it?

Cultural values

29. When you interact with Americans, have you noticed that either you or they are uncomfortable because of any of the following circumstances:

The distance between you and the other person

A tendency to touch others while talking Frequency and length of visual contact

Effusive greeting and a short and cold response

Visiting somebody who told you to do so and discovering that you were not expected

Others (Specify): 
30. Americans plan toward the future and live for the Euture; Latin Americans think and live in the present. Has this caused you any problem in your relationships and/or your studies?

Yes

No

31. Is it been easy for you to live in a materialistic society?

Yes

No

32. In your opinion, in the costa Rican culture it is more important to:

Do things all the time

Do fewer things

33. Do you find any differences regarding this matter between the American and the Costa Rican cultures?

Yes

No

34. If the answer is yes, does this disturb you?

Yes

No

35. What do you think is the American's attitude toward the environment

Yes

No

36. If the answer is affirmative, what kind of reaction does this cause for you?

Positive Neutral Negative

37. Has it been problematic to you, in any sense, to live in a society in which individualism is a predominant value?

Yes

No 
38. Has it been difficult for you, in any way, to deal with the prevailing competitive attitude of this society?

Yes

No

39. Do you have problems regarding punctuality (business appointments, school, social activities, etc.)? Yes

No

4ø. Have you encountered any conflict when comparing your concepts about the family to those of the American society?

Yes

No

41. Has it been easy for you to make friends in the U.S.? Yes No

42. Do you think that there are differences regarding the friendship concept between Americans and Costa Ricans? Yes No

43. What other attitudes, behavior or beliefs of the American culture have gained your attention? List them according to:

Like Dislike

Comments: 
Interaction

44. Do you feel confortable interacting with classmates, friends, in social activities, business, etc.?

Yes

No

45. You interact more with: (Rank according to frequency, 1 is the highest, 4 the lowest)

Americans

Costa Ricans

Both

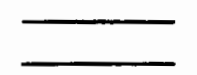

Other foreign students

Other (Specify):

46. Do you often attend social, cultural or sport activities in your community?

Yes

No

47. To what extent do you think you know the values, beliefs and norms that prevail in the American culture?

Not at all

More or less

We 11

Very well

48. What is your opinion about the American life style, values and customs:

Positive Neutral

Negative None

No opinion 
49. Do you believe without doubt that the Latin American

life style, customs, beliefs, and in general the world view are better than those of America?

Yes

No

50. Do you feel accepted by the American society? Yes No

Adaptation

51. Have you been through a period of confusion and fatigue due to the noticeable differences regarding behavior, life style, world view, etc.?

Yes

No

52. Do you feel this period is over?

Yes

No

(If Yes, go to the next question.)

(If No, go to question \#54.)

53. How did you know that this maladaptive period was over? (Check all that apply)

Began to feel more comfortable in your personal relationships

You felt more relaxed and free

Everything started to be easier for you

Began to enjoy your stay

Others (Specify): 
54. If your answer to the question \#52 is no, please write down the things that bother you or you do not quite understand:

55. How do you cope with the distressing

feelings of the adjustment process? (Check one or more alternatives)

Reproducing your own reality

in the new culture

Feeling overwhelmed by the cultural differences between your own culture and those of the one you are visiting

Feeling alienated and out of place (Identity crisis)

Learning to recognize the cultural differences and similarities (Being more flexible)

Accepting and using with confidence the behaviors of each culture

56. If you have lived in this country more than one year, you consider that:

You feel at home

There are groups you would consider yourself as part of, and you are not a total stranger within this culture any longer

You now command English language and that you have increased ability to behave appropriately in different situations 
It is possible for you

to match your own attitudes

and values with those of

the American culture

You have replaced the values

of your own culture with

those of the host culture

57. You have tried to solve your adjustment problems by:

Professional help

Classmates and/or friends' support

Seeking help

in your sponsor organization

You let time go by

\section{Al 1}

None

Others (Specify):

58. You began to communicate and interact better with Americans when:

Your English improved.

Everything started

to make sense for you.

You began to be more receptive and flexible about the local customs.

All

None

Other (Specify): 
Attitudes

59. Do you believe that everybody, no matter where he or she comes from, shares the same values, beliefs, behaviors and customs?

Yes

No

60. Everybody is the same because we are a product of a superior force or entity. To the extent that everyone has the same functions and physical needs, the surrounding environment does not matter. Do you agree with this statement?

Yes

No

61. Is it your opinion that there are more cultural

similarities than differences among people, regardless of their culture?

Yes

No

62. What is your attitude toward the differences between your own culture and the American culture?

Acceptance

Respect

Rejection

Adoption of the new culture

63. Did you try to change your customs and way of thinking because you consider that those belonging to the host culture are better?

Yes

No

64. Have you been able to understand the values and use customs of the host culture without losing your own?

Yes

No 
65. Do you think that people's behavior is based upon the different values that form their culture?

Yes

No

66. Are you aware of the values, concepts, beliefs, and customs that constitute your own culture?

Yes

No

Could you indicate some?

67. Do you tolerate the behavior and way of thinking of Americans?

Yes

No

68. When you relate with other people, have you

experienced an inner conflict over whether you should use your values and behavior or those belonging to the host culture?

Yes

No

69. Have you felt, at any moment, that you are losing your own culture?

Yes

No

70. Are you able to apply the behavior patterns of the culture you are interacting in and go back to your own culture without a problem?

Yes

No

71. Do you think that you have experienced the host culture enough to be able to behave "appropriately" without having to think about what you are doing?

Yes

No 
72. If the answer is yes, do you feel respect for the differences and also respect for your own identity? Yes

No

73. Do you feel now that your identity is composed of elements of different cultures or that you are in a process where you feel that you are becoming a part of one culture and at the same time moving away from yours?

Yes

No

74. Do you believe that you are capable of analyzing a situation from the point of view of two or more cultural perspectives?

Yes

No

75. Even though you have experienced other cultures, do you feel that your actions are governed by only one culture?

Yes

No

76. Do you think that there is:

Only one world view, that there is only one unique and "correct" way of behaving and thinking That the former statement is relative to culture Do not know Other (Specify):

77. OBSERVATIONS, COMMENTS: 
APPENDIX B

INVENTORY OF EXPECTED PROBLEMS OF

COSTA RICAN GRADUATE STUDENTS 


\section{INVENTORY OF EXPECTED PROBLEMS \\ OF COSTA RICAN STUDENTS}

I. ACADEMIC CONTEXT PROBLEMS

Relationship with faculty

Relationship with students

Student's role

II. PERSONAL PROBLEMS

Loneliness

Homesickness

III. SOCIAL PROBLEMS

Social interaction with Americans

Making friends

Establishing meaningful relationships

Being isolated from the mainstream

IV. COMMUNICATION PROBLEMS

Language

Phatic Communication

Nonverbal: time; proxemics; touching; and eye contact.

High anxiety 
V. VALUE DifFERENCES

Competition

Materialism

Individual ism

Family relations

Time orientation 
APPENDIX C

INTERVIEW SCHEDULE 


\section{INTERVIEW SCHEDULE}

Sex

Age

Study Area

Undergraduate Graduate

How long have you been here?

How much longer will you be here?

1. Were you fluent in English when you arrived in the U.S.?

2. What are the major difficulties you have encountered, if any, as a student in the U.S.?

3. Have you faced difficulties in the academic area such as differences in the educational system, the student's role, relationship with faculty or relationship with classmates? To what would you attribute them?

4. How satisfied are you with your social 1 ife and personal relationships? Do you miss your family and friends?

5. Do you interact socially with Americans? How would you describe those relations? Do you have any problems making friends? 
6. What kind of problems have you experienced when you relate with Americans? Language problems, or, for example, the distance you keep between you and the other person, or lack of physical contact?

7. Have you noticed difficulties regarding the use of time? "Tica" hour versus American Time. Being late for professional or social activities. Problems handing papers in?

8. Have you experienced times in which you feel depressed, anxious, or over-stressed?

9. Could you identify characteristics of the American culture that conflict with values of the Costa Rican culture? (Competition, individualism, materialism, family, friendship)

10. Do you feel at home here? How comfortable do you feel in the U.S.? Do you feel that you are a part of this society?

11. What of the mentioned problems do you think are the most intense in your case?

12. Comments. 